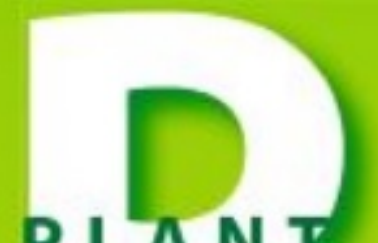

PLANT

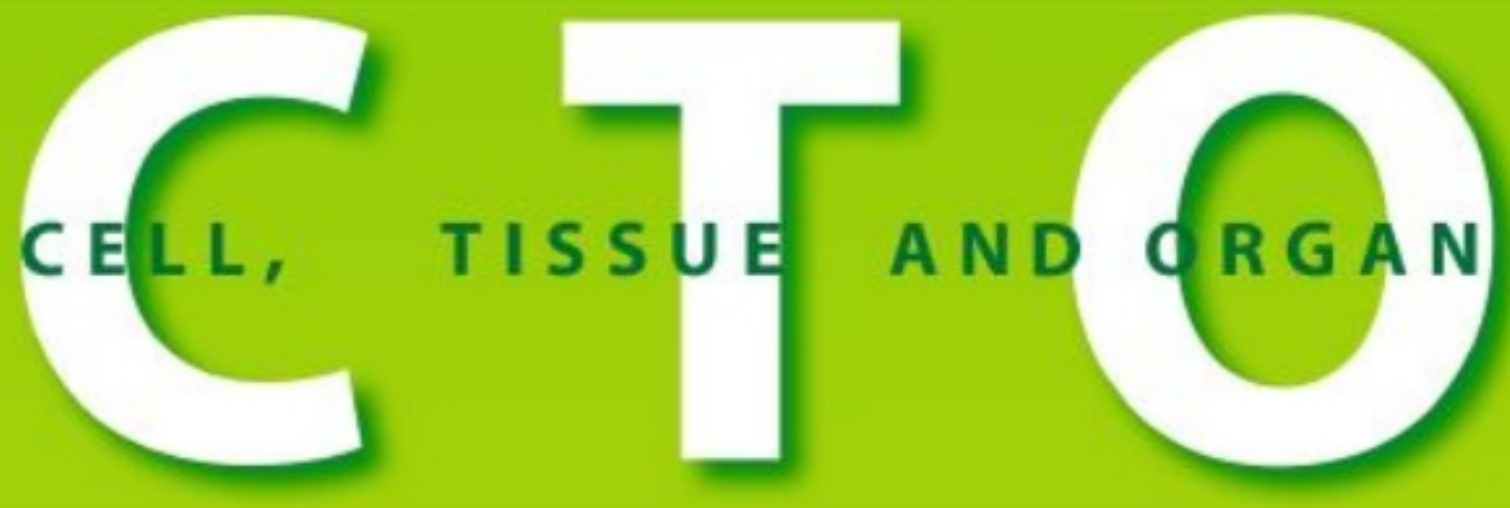

CULTURE
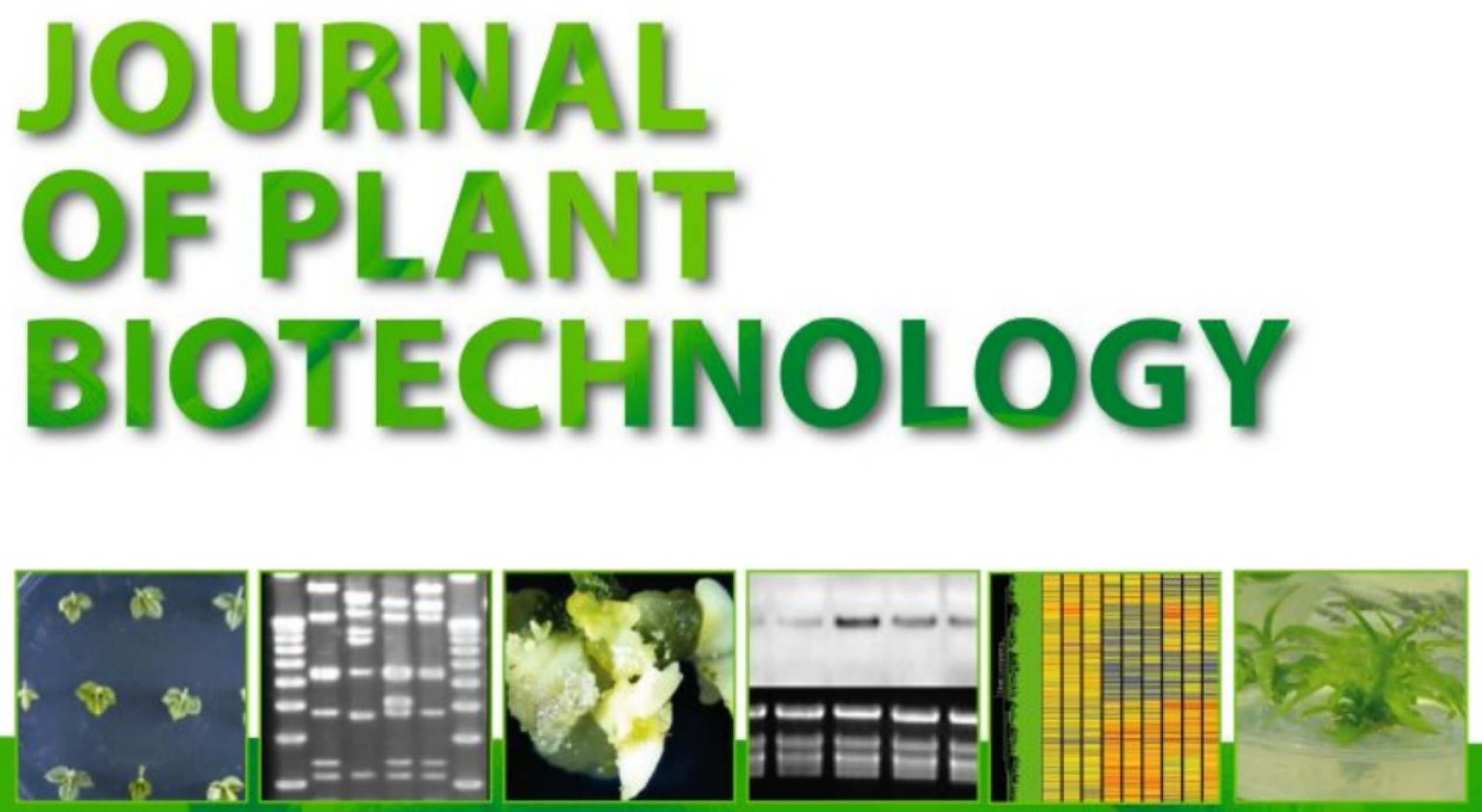

Springer 


\section{Springer}

\section{Plant Sciences Home > Life Sciences > Plant Sciences}

\section{P CTJOC}

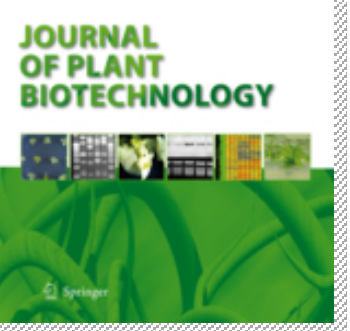

Journal of Plant Biotechnology

Editor-in-Chief: Sergio J. Ochatt

ISSN: 0167-6857 (print version)

ISSN: 1573-5044 (electronic version)

Journal no. 11240

\section{5,21 € : Personal Rate e-only}

\section{Get Subscription}

:: Online subscription, valid from January through December of current calendar year

$\because:$ Immediate access to this year's issues via SpringerLink

:: 4 Volume(-s) with 12 issue(-s) per annual subscription

:: Automatic annual renewal

:: More information: >> FAQs // >> Policy

\section{Editor-in-Chief}

Dr. Sergio J. Ochatt

INRA, Dijon, France

\section{Associate Editors}

Dr. Ali R. Alan

Pamukkale University, Denizli, Turkey

Dr. Fredy Altpeter

University of Florida, IFAS, Gainesville, FL, USA

Dr. Margherita Beruto

Istituto Regionale Per La Floricoltura, San Remo, Italy

Dr. Ming-Tsair Chan

Academia Sinica, Taipei, Taiwan

Dr. Sergey Dolgov

Institute of Bioorganic Chemistry RAS, Pushchino, Russia 
Dr. Klaus Eimert

Geisenheim Research Center, Geisenheim, Germany

Dr. Henryk Flachowsky

Julius Kühn-Institut, Dresden,Germany

Dr. Alison Ferrie

NRC Plant Biotechnology Institute, Saskatoon, Canada

Prof. Danny Geelen

Ghent University, Gent, Belgium

Dr. Maria Antonietta Germanà

University of Palermo, Palermo, Italy

Dr. Wen-Wu Guo

Huazhong Agricultural University, Wuhan, China

Dr. Yujin Hao

Shandong Agricultural University, China

Dr. Konstantin Kiselev

Far East Branch of Russian Academy of Sciences, Vladivostok, Russia

Dr. Nobuhiro Kotoda

National Institute of Fruit Tree Science, Morioka, Japan

Dr. Sergei Krasnyanski

North Carolina State University, Raleigh, NC, USA

Dr. Jochen Kumlehn

IPK-Gatersleben, Germany

Dr. Maurizio Lambardi

CNR-IVALSA, Trees and Timber Institute, Florence, Italy

Dr. Yi Li

University of Connecticut, Storrs, CT, USA

Dr. Silvia Moreno

Fundación Instituto Leloir, Buenos Aires, Argentina

Dr. Francisco de Assis A. Mourão Filho

Universidade de São Paulo, Brazil

Dr Margarida M. Oliveira

Instituto de Biologia Experimental e Tecnológica, Oeiras, Portugal

Prof. Wagner C. Otoni

Federal University of Viçosa, Viçosa, Brazil

Dr. Bart Panis

K.U. Leuven, Leuven, Belgium

Dr. Ranjith Pathirana

The New Zealand Institute for Plant \& Food Research Limited, Palmerston North, New Zealand

Dr. Manoj Prasad

NIPGR Aruna Asaf Ali Marg, New Delhi, India 
Prof. María Angeles Revilla Bahillo

Universidad de Oviedo, Spain

Dr. Sergio Rosales-Mendoza

Universidad Autónoma de San Luis Potosí, St. Luis Potosi, Mexico

Dr. Jose M. Segui-Simarro

Universitat Politècnica de València, Valencia, Spain

Dr. Kexuan Tang

Shanghai Jiao Tong University, Shanghai, China

Dr. Qiaochun Wang

Northwest A\&F University, Shaanxi, China

Dr.Pamela J. Weathers

Worcester Polytechnic Institute, Worcester, MA, USA

Dr. Traud Winklemann

Leibniz University Hannover, Hannover, Germany

READ THIS JOURNAL ON SPRINGERLINK

Online First Articles

FOR AUTHORS AND EDITORS

\section{i. 2017 Impact Factor}

Aims and Scope
Submit Online
Open Choice - Your Way to Open Access
Instructions for Authors
Types of papers

SERVICES FOR THE JOURNAL
Contacts
Shipping Dates
Order Back Issues
Article Reprints
Bulk Orders

Download Product Flyer 
Get the table of contents of every new issue published in Plant Cell, Tissue and Organ Culture (PCTOC).

\section{LOGIN}

Please send me information on new Springer publications in Plant Sciences.

RELATED BOOKS - SERIES - JOURNALS

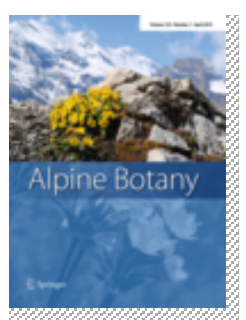

Journal

\section{Alpine Botany}

Editor» Editor-in-Chief: Jürg

Stöcklin 


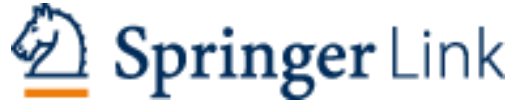

$\underline{\text { Plant Cell, Tissue and Organ Culture (PCTOC) }}$

All Volumes \& Issues

ISSN: 0167-6857 (Print) 1573-5044 (Online)

\section{In this issue (14 articles)}

1. Original Article

Expression of a fungal ferulic acid esterase in suspension cultures of tall fescue (Festuca arundinacea) decreases cell wall feruloylation and increases rates of cell wall digestion

Phillip Morris, Sue Dalton, Tim Langdon... Pages 181-193

2.

Original Article

Antimicrobial and hormetic effects of silver nanoparticles on in vitro regeneration of vanilla (Vanilla planifolia Jacks. ex Andrews) using a temporary immersion system

J. L. Spinoso-Castillo... Pages 195-207

3.

Original Article

High light intensity stress as the limiting factor in micropropagation of sugar maple (Acer saccharum Marsh.)

Amritpal S. Singh, A. Maxwell P. Jones... Pages 209-221

4 .

Original Article

Overexpression of the gibberellin 20 -oxidase gene from Torenia fournieri resulted in modified trichome formation and terpenoid metabolities of Artemisia annua $L$.

Phithak Inthima, Masaru Nakano... Pages 223-236 
5 .

Original Article

Genome-wide identification and expression analysis of polyamine oxidase genes in upland cotton (Gossypium

hirsutum L.)

Xin-Qi Cheng, Xue-Feng Zhu, Wen-Gang Tian... Pages 237-249

6.

Original Article

Promotion of artemisinin content in Artemisia annua by overexpression of multiple artemisinin biosynthetic pathway genes

$\underline{\text { Pu Shi, }}$ Xueqing Fu, Meng Liu, Qian Shen... Pages 251-259

7.

Original Article

Rapid and accurate early-stage detection of T-DNA/plant flanking sequences of resistant kumquats

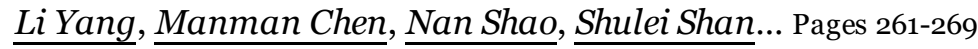

8.

Original Article

Wheat ZFP gene TaZFP593; I mediates the $\mathrm{N}$-starvation adaptation of plants through regulating $N$ acquisition and the ROS metabolism

Yaoxian Chen, Mengya Yang, Weiwei Ding... Pages 271-288

9 .

Original Article

Enhanced production of metabolites by elicitation in Opuntia ficus-indica, Opuntia megacantha, and Opuntia streptacantha callus 
Nancy Gabriela Camarena-Rangel... Pages 289-298

10.

Original Article

Generation of genetically stable transformants by

Agrobacterium using tomatofloral buds

Miduthuri Satya Sharada, Alka Kumari... Pages 299-312

11.

Original Article

In vitro shoots from root explant, their encapsulation, storage, plant recovery and genetic fidelity assessment of

Limonium hybrid 'Misty Blue': aflorist plant

Shankhamala Bose, Joydeep Karmakar... Pages 313-324

12.

Original Article

Modeling some mineral nutrient requirements for micropropagated wild apricot shoot cultures

Irina Y. Kovalchuk, Zinat Mukhitdinova... Pages 325-335

3.

Original Article

Overexpression of a cytosolic ascorbate peroxidase from

Panax ginseng enhanced salt tolerance in Arabidopsis

thaliana

Johan Sukweenadhi, Yu-Jin Kim, Shadi Rahimi... Pages 337-350

14 .

Original Article

Kanamycin selection in temporary immersion bioreactors allows visual selection of transgenic citrus shoots

$\underline{\text { Yosvanis Acanda, }}$ Michel Canton, Hao Wu... Pages 351-357 
Support 


\section{Overexpression of a cytosolic ascorbate peroxidase from Panax ginseng enhanced salt tolerance in Arabidopsis thaliana}

\section{Johan Sukweenadhi, Yu-Jin Kim, Shadi}

Rahimi, Jeniffer Silva, Davaajargal Myagmarjav, Woo Saeng Kwon \& DeokChun Yang

Plant Cell, Tissue and Organ Culture (PCTOC)

Journal of Plant Biotechnology

ISSN 0167-6857

Volume 129

Number 2

Plant Cell Tiss Organ Cult (2017) 129:337-350

DOI 10.1007/s11240-017-1181-z
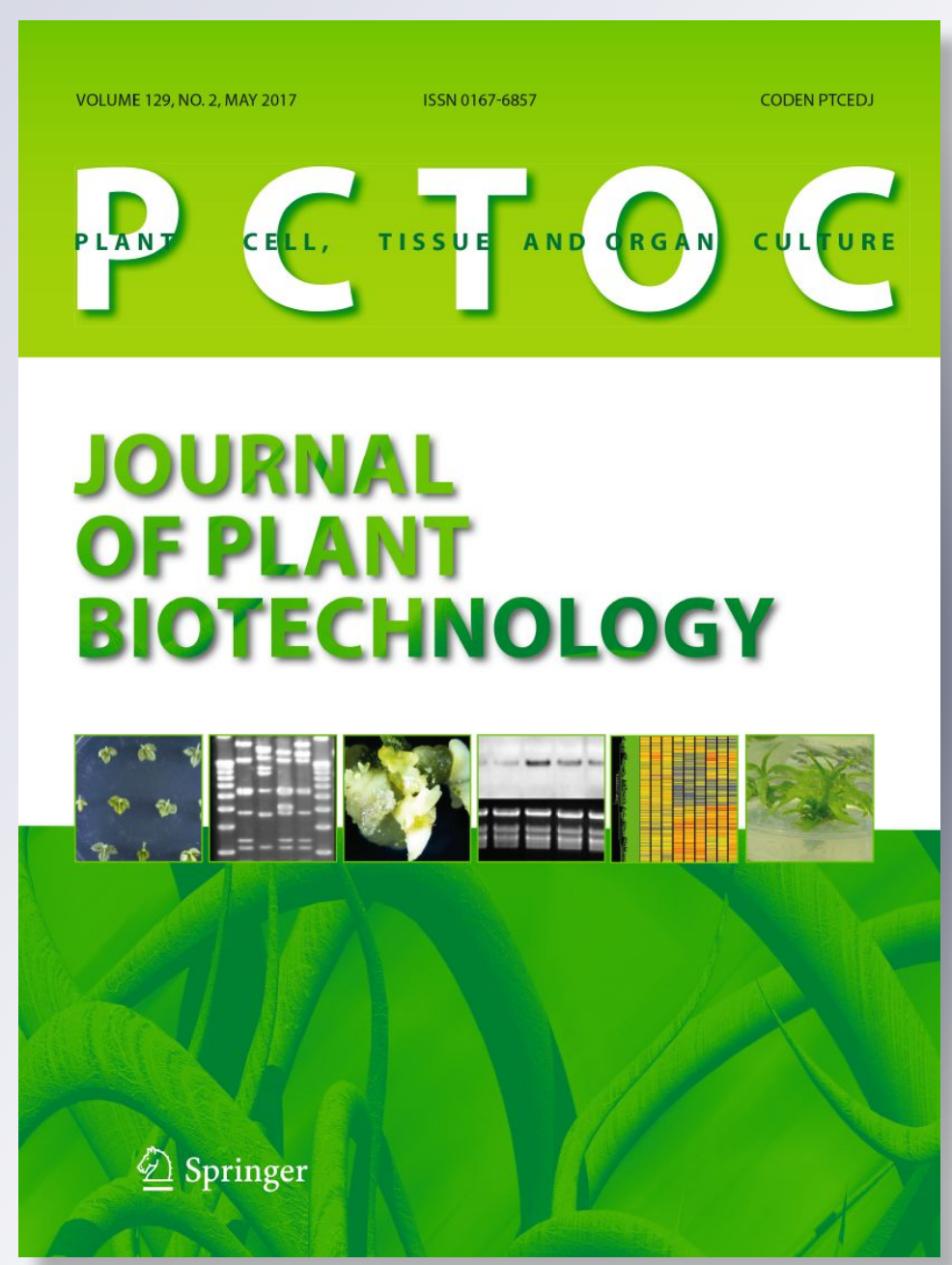

Springer 
Your article is protected by copyright and all rights are held exclusively by Springer Science +Business Media Dordrecht. This e-offprint is for personal use only and shall not be selfarchived in electronic repositories. If you wish to self-archive your article, please use the accepted manuscript version for posting on your own website. You may further deposit the accepted manuscript version in any repository, provided it is only made publicly available 12 months after official publication or later and provided acknowledgement is given to the original source of publication and a link is inserted to the published article on Springer's website. The link must be accompanied by the following text: "The final publication is available at link.springer.com". 


\title{
Overexpression of a cytosolic ascorbate peroxidase from Panax ginseng enhanced salt tolerance in Arabidopsis thaliana
}

\author{
Johan Sukweenadhi ${ }^{1} \cdot$ Yu-Jin Kim ${ }^{2}$ (D) Shadi Rahimi ${ }^{1} \cdot$ Jeniffer Silva $^{1}$ • \\ Davaajargal Myagmarjav ${ }^{1}$. Woo Saeng Kwon ${ }^{1}$ Deok-Chun Yang ${ }^{1,2}$
}

Received: 30 June 2016 / Accepted: 24 January 2017

(C) Springer Science+Business Media Dordrecht 2017

\begin{abstract}
Ascorbate peroxidase (APX) plays an essential role in the antioxidant defense mechanism in the plant, serving in the ascorbate-glutathione cycle for the cellular $\mathrm{H}_{2} \mathrm{O}_{2}$ metabolism process. As the perennial plant, Panax ginseng Meyer encounters a lot of unfavorable growth conditions, and among them soil salinity significantly decreases the yield. Two APX genes from Panax ginseng were isolated and designated as $P g A P X 1$ and $P g A P X 2$, which are most similar with previously characterized cytosolic APX of Daucus carota and Spuriopimpinella brachycarpa, as revealed by sequence analysis of their deduced amino acid sequences. PgAPXs transcripts are most abundant in leaf tissue, whereas $P g A P X 1$ expression level was higher compared to $P g A P X 2$. Consistent with higher $P g A P X 1$ expression during salt stress in ginseng, $P g A P X 1$ overexpressing Arabidopsis lines $\left(P g A P X 1_{\text {ox }}\right)$ increased the germination rate and root length compared with wild-type (WT) under $200 \mathrm{mM} \mathrm{NaCl}$ stress treatment. Furthermore, higher chlorophyll content, relative water content, total APX activity, proline content, and lower $\mathrm{H}_{2} \mathrm{O}_{2}$ accumulation were shown in $P g A P X 1_{o x}$ plants compared to WT
\end{abstract}

Electronic supplementary material The online version of this article (doi:10.1007/s11240-017-1181-z) contains supplementary material, which is available to authorized users.

Yu-Jin Kim

yujinkim@khu.ac.kr

$\triangle$ Deok-Chun Yang

dcyang@khu.ac.kr

1 Graduate School of Biotechnology and Ginseng Bank, College of Life Sciences, Kyung Hee University, Yongin, South Korea

2 Department of Oriental Medicinal Biotechnology, College of Life Science, Kyung Hee University, Yongin, South Korea under $200 \mathrm{mM} \mathrm{NaCl}$ stress condition. Transcription analysis showed that $P g A P X 1_{o x}$ Arabidopsis lines were more salttolerant by upregulating the ion homeostasis mechanism.

Keywords Oxidative stress $\cdot$ Ascorbate peroxidase $\cdot$ Salt stress $\cdot \mathrm{H}_{2} \mathrm{O}_{2} \cdot$ Panax ginseng

\section{Introduction}

Environmental stresses periodically affect plants during their cultivation. These conditions can disrupt the balance of cells metabolism, resulting in elevated reactive oxygen species (ROS) production, for instance, hydrogen peroxide $\left(\mathrm{H}_{2} \mathrm{O}_{2}\right)$, hydroxyl radical $(\mathrm{OH})$, singlet oxygen $\left({ }^{1} \mathrm{O}_{2}\right)$ and superoxide $\left(\mathrm{O}_{2}{ }^{-}\right)$. Recent study discovered a role of singlet oxygen as initiator of ROS systemic signals (Carmody et al. 2016). At the condition with no stresses, plants produce ROS which act in the oxidative signaling pathway and triggering a lot of cellular functions such as cell apoptosis, stress responses, and developmental processes (Apel and Hirt 2004; Ishikawa et al. 2013; Dietz et al. 2016). However, due to excessive stress exposure, plants can produce higher amount of ROS which induce oxidative damage and reduce plant productivity (Shigeoka et al. 2002).

An efficient antioxidant mechanism in plant integrates antioxidants network and ROS-scavenging enzymes in diverse locations in organelles, cells, and tissues (Ara et al. 2013). Antioxidant enzymes consist of ascorbate peroxidase (APX), superoxide dismutase (SOD), peroxiredoxin (PrxR), glutathione peroxidase (GPX), and catalase (CAT). APX (EC 1.11.1.1) enzymes have an essential function in regulation of ROS levels and $\mathrm{H}_{2} \mathrm{O}_{2}$ scavenging networks from cytosol and chloroplast of plant cells. APX detoxify $\mathrm{H}_{2} \mathrm{O}_{2}$ utilizing ascorbate (AsA) as a substrate. Through 
glutathione (GSH) utilization, electron transfer from ascorbate to a peroxide is catalyzed by dehydroascorbate (DAsA) reductase, yielding DAsA and water as the products. Thus, a combination of APX and AsA-GSH cycle serves to prevent the $\mathrm{H}_{2} \mathrm{O}_{2}$ toxicity in the plant in response to multiple stress reactions (Shigeoka et al. 2002; Blokhina et al. 2003).

APX has been discovered in various cellular compartments: stroma (Asada 1992) and thylakoid membrane (Miyake and Asada 1992) in chloroplasts, cytosol (Mittler and Zilinskas 1991), microbodies (Yamaguchi et al. 1995), and mitochondrial membrane (Leonardis et al. 2000). In Arabidopsis, chloroplastic APX; stroma APX (At4g08390) and thylakoid APX (Atlg77490) were found to contribute of photoprotection by regulation of $\mathrm{H}_{2} \mathrm{O}_{2}$-responsive genes during photooxidative stress (Maruta et al. 2010), while cytosolic APX1 (At1g07890) was shown to participate in a various biological processes (Davletova et al. 2005). The cytosolic APX1 was constitutively expressed in leaves, stems, and roots (Zimmermann et al. 2004) and it has a common defense role during abiotic and biotic stresses (Wu et al. 2014).

cDNAs encoding the cytosolic APX isoenzymes were isolated and well-studied from many plants, such as pea (Mittler and Zilinskas 1991), Arabidopsis (Kubo et al. 1992), corn (Koshiba 1993), spinach (Webb and Allen 1995), tobacco (Orvar and Ellis 1995), rice (Teixeira et al. 2004), cowpea (D'Arcy-Lameta et al. 2006), rose gum (Teixeira et al. 2005), and tomato (Najami et al. 2008). APX isogenes' expression varies depending on tissue (Teixeira et al. 2006), developmental stage (Agrawal et al. 2003), and various environmental stimuli such as high light (Fryer et al. 2003), salt stress (Menezes-Benavente et al. 2004), $\mathrm{H}_{2} \mathrm{O}_{2}$ stress (Yoshimura et al. 2000), heat stress (Bonifacio et al. 2011), cold stress (Zhang et al. 1997), drought stress (Rosa et al. 2010), and pathogen attack (Agrawal et al. 2003).

Panax ginseng Meyer (Korean ginseng) is known to possess various pharmacological properties, such as immunostimulant, anticancer, antiemetic, antiproliferative, and antioxidant properties, along with other health benefits (Chung et al. 2016). As a herbaceous perennial plant, ginseng encounters many unfavorable growth circumstances, such as drought, temperature fluctuations, and salinity (Ashraf and Foolad 2013). Among these stresses, soil salinity is crucial environmental stress which significantly decreases the yield of various crops (Zhu 2001) including ginseng growth (Kim et al. 2015). Despite the importance of ginseng, its antioxidant enzyme system is not yet well-studied, and their role in the salt tolerance mechanism remains vague. In the research presented here, we isolated and cloned $A P X$ gene from $P$. ginseng, examined the phylogenetic relationship with those in other plants, and overexpressed into Arabidopsis to understand the possible role of ginseng $A P X$ against salinity condition. Overexpression of $P g A P X$ enhanced salt stress tolerance in Arabidopsis via increase of APX activity and proline content, and decrease in the accumulation of $\mathrm{H}_{2} \mathrm{O}_{2}$. It also suggested its possible application in improving the tolerance abilities in crops by the way of genetic modification.

\section{Materials and methods}

\section{Sequence analysis and cloning of PgAPX}

cDNA clones encoding the APX genes were found from our EST library constructed previously (Kim et al. 2006) and sequenced by Genotech (Daejeon, Republic of Korea). After sequencing analysis, we found two full-length cDNAs, designated as PgAPX1 and PgAPX2 ( $P$. ginseng ascorbate peroxidase). By NCBI BLAST feature, the homologous proteins were searched from deduced amino acid sequences as input. Multiple alignments of APXs isolated from $P$. ginseng and other species APXs were performed using ClustalX. A neighbor-joining based phylogenetic tree was constructed using MEGA6 software. Molecular mass, the number of amino acid residue, and isoelectric point (pI) of PgAPX proteins deducted from the open reading frames (ORF) of mature protein were analyzed by ExPASy Server according to Gasteiger et al. (2005). The hydropathy value was determined following Kyte and Doolittle method (1982), while the secondary structure was predicted using SOPMA (Geourjon and Deleage 1995). Conserved motifs on APX were predicted by MEME (Bailey et al. 2009). SWISS-MODEL Workspace in automated mode was utilized to predict a three-dimensional model using APX as a template (Arnold et al. 2006) and then the 3-D structure was visualized using UCSF Chimera package. Furthermore, promoter sequence of $P$. ginseng APX (pPgAPX) and gene structure were identified based on ginseng genome database (http://im-crop.snu.ac.kr/new/ index.php). PlantCARE was used to estimate cis-acting regulatory elements comprised of promoter region (Lescot et al. 2002). Amplified fragments of pPgAPX were cloned, sequenced, and fused with 3-glucuronidase (GUS) reporter gene in pCAMBIA 1300, using specific primers embedded with PstI and SalI (Supplementary Table 1), designated as $p P g A P X 1:: G U S$ and $p P g A P X 2:: G U S$. Histochemical analysis through GUS staining for each $p P g A P X 1:: G U S$ and pPgAPX2::GUS Arabidopsis line was conducted by using 5 biological replicates. $P g A P X 1$ overexpression was carried on using pCAMBIA1390 containing CFP (cyan fluorescent protein) and it was expressed under the cauliflower mosaic virus (CaMV) $35 \mathrm{~S}$ promoter. From $P$. ginseng cDNA, $P g A P X 1$ gene was amplified by PCR using specific primers 
embedded with SalI and EcoRI (Supplementary Table 1), designated as 35S:PgAPX1:CFP.

\section{Localization of PgAPX1}

Subcellular localization analysis of PgAPX1 was done utilizing four-day-old seedlings of $P g A P X 1_{\mathrm{ox}}$ lines. Leica TCS SP5 laser scanning confocal microscope was used for the analysis. With the excitation wavelength of $488 \mathrm{~nm}$ and an emission wavelength of 505-530 nm, CFP fluorescent signals were visualized. Meanwhile, at emission wavelength longer than $650 \mathrm{~nm}$, the red auto-fluorescence of chlorophylls was visualized.

\section{Plant materials and stress treatment}

The leaf, stem, and root of four-year-old $P$. ginseng cultivated on ginseng field (Kyung Hee University, South Korea, provided by the Ginseng Bank of Korea) were used for checking the abundance of $P g A P X$ genes. For checking the expression of $P g A P X \mathrm{~s}$ under salt stress, two-yearold ginseng roots were used. The Arabidopsis thaliana (Columbia ecotype) was used in this study as the model plant. Surface-sterilized seeds were sown on $1 / 2$ MS medium containing $1 \%$ sucrose and $0.8 \%$ agar with $\mathrm{pH} 5.7$ adjustment using $\mathrm{KOH}$. Two-day-old cold-treated seeds were germinated under long-day conditions (16 h light/ $8 \mathrm{~h}$ dark) at $23^{\circ} \mathrm{C}$. Arabidopsis transformation of all gene constructs was done using Agrobacterium tumifaciens via floral dip according to Clough and Bent's method (1998). Hygromycin $(50 \mu \mathrm{g} / \mathrm{mL})$-containing plates were used to get transgenic (T2) lines. Utilizing promoter construct, the histochemical analysis was done based on various developmental stages and under salt stress treatment (200 and $300 \mathrm{mM} \mathrm{NaCl}$ ). For measuring germination rate, 100 sterilized seeds of Arabidopsis PgAPXI ${ }_{\mathrm{ox}}$ lines were sown on each $1 / 2 \mathrm{MS}$ medium with various $\mathrm{NaCl}$ concentrations $(0$, $50,150,300 \mathrm{mM})$. It was measured every $12 \mathrm{~h}$ by observing penetration of the radicles in seed coats. For measuring root growth, approximately 500 sterilized seeds of Arabidopsis $P g A P X 1_{\text {ox }}$ lines were sown on $1 / 2 \mathrm{MS}$ medium and 100 of four-day-old seedlings were transferred onto each $1 / 2 \mathrm{MS}$ medium with various $\mathrm{NaCl}$ concentrations $(0,50$, 150 and $300 \mathrm{mM}$ ), for further vertical growth for another 12 days. Three independent replicates were conducted for each treatment of germination test and root elongation test. For salt stress treatment, 60 of ten-day-old seedlings were transplanted into the vermiculite: peat moss: perlite $(1: 1: 1)$ mixture and allowed to grow in the same light/dark conditions. 30 of three-week-old seedlings on pots were watered with $200 \mathrm{mM} \mathrm{NaCl}$ solution while remaining seedling were watered normally. At various time points of post-treatment, three biological replicates of leaves samples were collected for RNA isolation. The plant samples were quickly frozen using liquid nitrogen and stored at $-70^{\circ} \mathrm{C}$ until needed.

\section{Real-time quantitative RT-PCR}

Total RNA was extracted from plant samples using the RNeasy mini kit (Qiagen, Valencia, CA, USA) and used as a template for reverse transcription using oligo(dT)15 primer $(0.2 \mathrm{mM})$ and RevertAid H Minus Reverse Transcriptase (200 U/ $\mu \mathrm{L})$ (ThermoFisher Scientific, South Korea). Using $100 \mathrm{ng}$ of cDNA in a $15-\mu \mathrm{L}$ total reaction volume of SYBR ${ }^{\circledR}$ Green Sensimix Plus Master Mix (Quantace, Watford, England), Real-time PCR was executed. Amplification, detection, and data analysis were carried out with a CFX 96/ Connect Real-Time PCR system (BIO-RAD, South Korea). Specific primers for PgAPXI, $P g A P X 2$, and other genes were used to perform real-time PCR (Supplementary Table 1, Supplementary Fig. 1). The thermal cycler conditions were used as follows: $3 \mathrm{~min}$ at $95^{\circ} \mathrm{C}$, followed 40 cycles of $95^{\circ} \mathrm{C}$ for $30 \mathrm{~s}, 56.4-62.4{ }^{\circ} \mathrm{C}$ for $50 \mathrm{~s}$, and $72^{\circ} \mathrm{C} 30 \mathrm{~s}$. The annealing temperature of each gene is available in Supplementary Table 1. At the last step of each cycle, the fluorescent product was detected. The number of cycles at which it has significantly higher fluorescence intensity than the background fluorescence at the initial exponential phase of PCR amplification is designated as the threshold cycle $(\mathrm{Ct})$. The $\mathrm{Ct}$ value for $\beta$-actin was used to normalize $\mathrm{Ct}$ value of $P g A P X$ before calculated relatively to a calibrator using the formula $2^{-\Delta \Delta \mathrm{Ct}}$ to determine the relative fold differences in template abundance for each sample. The primer efficiencies were determined according to the method by Livak and Schmittgen (2001) to validate the $\Delta \Delta \mathrm{Ct}$ method. The efficiencies of the gene and the internal control $\beta$-actin were equal when the observed slopes were near to zero. Three independent experiments were performed.

\section{$\mathrm{H}_{2} \mathrm{O}_{2}$ detection by $3,3^{\prime}$-diaminobenzidine (DAB) staining}

Modified from previous methods (Daudi et al. 2012), DAB staining was used to do in situ detection of $\mathrm{H}_{2} \mathrm{O}_{2}$. The harvested leaf samples were placed in a 12-well-plate. Three $\mathrm{mL}$ of DAB staining solution was applied to the leaves in the well until fully immersed. As the control, $2 \mathrm{~mL}$ of $10 \mathrm{mM} \mathrm{Na} \mathrm{HPO}_{4}$ was applied to replicate leaves. The 12-well plates covered with aluminum foil were placed in a desiccator and gently vacuumed for $5 \mathrm{~min}$, and were shaken for $3 \mathrm{~h}$ at $100 \mathrm{rpm}$. After the incubation, bleaching solution (ethanol: glycerol: acetic acid $=3: 1: 1$ ) was given replacing DAB staining solution, boiled on a water bath for $15 \mathrm{~min}$, and replaced by fresh bleaching solution. After incubation 
at room temperature for $30 \mathrm{~min}$, the photograph was taken under uniform lighting.

\section{Chlorophyll content assay}

According to Lichtenthaler method (1987) with some modification, $60 \mathrm{mg}$ leaves were ground into powder with liquid nitrogen and moved to a $1.5 \mathrm{~mL}$ tube. Mix with $1 \mathrm{~mL}$ of $80 \%$ acetone and stand in the dark for overnight. After centrifugation at $4{ }^{\circ} \mathrm{C}, 2500 \mathrm{rpm}$ for $15 \mathrm{~min}$, the supernatant was moved to a new tube. The absorbance of chlorophyll was measured using spectrophotometry with $80 \%$ acetone as a blank control. The concentrations of chlorophyll are calculated as follows; Chlorophyll a $=12.72 *$ A663 $-2.59 *$ A645, Chlorophyll $\mathrm{b}=22.9 * \mathrm{~A} 645-4.67 * \mathrm{~A} 663$ and Total chlorophyll $=20.31 *$ A645 + 8.05* A663.

\section{Relative water content (RWC) measurement}

Fully expanded terminal leaflets were sampled and fresh weight (FW) was recorded immediately. Turgid weight (TW) was achieved constant weight after overnight keeping the leaf in distilled water at $4{ }^{\circ} \mathrm{C}$ while dry weight (DW) was obtained constant weight after keeping the turgid leaf at $70^{\circ} \mathrm{C}$ oven. The formula is following: $\mathrm{RWC}=(\mathrm{FW}$ $-\mathrm{DW}) /(\mathrm{TW}-\mathrm{DW}) \times 100 \%$ (Tambussi et al. 2005).

\section{Proline determination}

Proline extraction was done using 50 times diluted fresh weight $(\mathrm{w} / \mathrm{v})$, in a 70:30 ethanol: water mixture $(\mathrm{v} / \mathrm{v})$. Extract was mixed with reaction mix (ninhydrin $1 \%(\mathrm{w} / \mathrm{v})$ in ethanol 20\% (v/v), acetic acid 60\% (v/v)) with equal volume under light-protected condition. The reaction mixture was heated at $95^{\circ} \mathrm{C}$ for $20 \mathrm{~min}$. After cooling to room temperature, it was spin down immediately then transferred to a microplate well and processed the absorbance read at $520 \mathrm{~nm}$. The amount of proline in the extracts:

Proline in nmol/mg FW or in $\mu \mathrm{mol} / \mathrm{g} \mathrm{FW}$

$$
=\left(\mathrm{Abs}_{\text {extract }}-\text { blank }\right) / \text { slope } \times \mathrm{Vol}_{\text {extract }} / \mathrm{Vol}_{\text {aliquot }} \times 1 / \mathrm{FW}
$$

$\mathrm{Abs}_{\text {extract }}$ is the extract absorbance value. Blank (expressed as absorbance) and slope (expressed as absorbance/nmol) are specified through linear regression, $\mathrm{Vol}_{\text {extract }}$ is the extract total volume, $\mathrm{Vol}_{\text {aliquot }}$ is the volume used in the assay, FW (expressed in $\mathrm{mg}$ ) is the amount of plant material used at first extraction process. It is presumed that $\mathrm{Abs}_{\text {extract }}$ is within the linear range. As standards, proline solutions ranging from 0.04 to $1 \mathrm{mM}$ were prepared in the same medium as the one that used for the extraction (Carillo et al. 2008).

\section{APX and SOD enzyme activity assay}

APX and SOD enzyme activity were determined following the method described by Venisse et al (2001) and Shafi et al (2015), respectively. Leaves were sampled, immediately weighted and ground. All the ground powder was collected into a $1.5 \mathrm{~mL}$ microtube in which $1 \mathrm{~mL}$ extraction buffer $(50 \mathrm{mM}$ sodium phosphate buffer- $\mathrm{pH} 7.5,1 \mathrm{mM}$ phenylmethylsulfonyl fluoride, $1 \mathrm{mM}$ polyethylene glycol, $8 \%(\mathrm{w} / \mathrm{v})$ polyvinylpyrrolidone, $0.01 \%(\mathrm{v} / \mathrm{v})$ Triton X-100) was added and vortex for a few seconds. The mixture was centrifuged at $4{ }^{\circ} \mathrm{C}, 13,000 \mathrm{rpm}$ for $20 \mathrm{~min}$. The supernatant was collected in a new microtube and incubated on ice for activity analysis. $1 \mathrm{~mL}$ APX reaction mixture (0.2 M Tris/HCl buffer, $\mathrm{pH} 7.8,0.5 \mathrm{mM} \mathrm{H}_{2} \mathrm{O}_{2}, 0.25 \mathrm{mM}$ ascorbic acid) was mixed with $50 \mu \mathrm{l}$ of the crude extract into a $1.5 \mathrm{~mL}$ microtube, and recorded the absorbance at $290 \mathrm{~nm}$ at the start point of time. The total SOD activity was measured by adding $25 \mu \mathrm{l}$ enzyme extract to reaction mixture $(1 \mathrm{~mL})$ containing $1.5 \mu \mathrm{m}$ riboflavin, $50 \mu \mathrm{m}$ NBT (nitroblue tetrazolium), $10 \mathrm{mM}$ Dl-methionine and $0.025 \%$ $(\mathrm{v} / \mathrm{v})$ triton-X 100 in $50 \mathrm{mM}$ phosphate buffer. After $5 \mathrm{~min}$, reaction sample was moved to the cuvettes and covered with parafilm to prevent the oxidation in the air. The ELISA reader (Synergy-2, Bio-Tek Instruments, Inc., Winooski, VT, USA) was used to read the absorbance at the specific wavelength Coomassie (Bradford) protein assay kit was used to determine the protein concentration of the samples. Value decline in absorbance at 290 and $560 \mathrm{~nm}$ represents decrease amount of ascorbate and NBT, respectively. One unit of enzyme activity was defined as the amount of enzyme that oxidized $1 \mu \mathrm{M}$ of substrate per min at $25^{\circ} \mathrm{C}$ $(\mu \mathrm{L} / \mathrm{mg}$ protein/min).

Enzyme activity $=[(\mathrm{A} 2-\mathrm{A} 1) /(\mathrm{T} 2-\mathrm{T} 1)] / \mathrm{mg}$ protein $=$ change of absorbance/per $\mathrm{mg}$ protein per min.

\section{Results and discussion}

\section{Sequence analysis and cloning of two PgAPXs}

APXs, especially the cytosolic APX, participate in the plant defense against oxidative stress (Shigeoka et al. 2002). Several previous studies demonstrated that cytosolic APX overexpression was significantly improving APX activity that protects plants from oxidative damage caused by a salt stress condition. For example, overexpression of Arabidopsis cytosolic APX (Badawi et al. 2004), pea cytosolic APX (Wang et al. 2005), Lycium chinense cytosolic $A P X$ in tobacco (Wu et al. 2014), rice OsAPXa and OsAPXb in Arabidopsis (Lu et al. 2007), and rice OsAPX2 in Alfalfa (Zhang et al. 2014), amends salt stress tolerance on transgenic plant at various responsive degree. The 
isolation and characterization of novel cDNAs of cytosolic $A P X$ is an access to further understanding of cytosolic $A P X$ gene. Thus, overexpressing this gene allows new perspectives about regulation and physiological function of these enzymes. In this study, we isolated a cytosolic $A P X$ gene from $P$. ginseng and its potential function in transgenic Arabidopsis were examined under salt stress condition.

From our $P$. ginseng EST library previously built (Kim et al. 2006), two different isozymes from more than ten cDNA clones encoding APX genes have been identified. The full-length cDNA sequences have been assigned to GenBank under the accession numbers (KX388539 and KX388540), named as PgAPX1 and PgAPX2 (P. ginseng ascorbate peroxidase). Both of PgAPX sequences have 91\% identity to each other. The PgAPXI and PgAPX2 ORF sequences were $753 \mathrm{bp}$ long encoding proteins with 250 amino acids in length, and $27.5 \mathrm{kDa}$ of molecular mass. Theoretical pI for PgAPX1 and PgAPX2 is 5.55 and 5.64, respectively. Amino acid sequences of PgAPX1 and PgAPX2 share higher degrees of identity (86 and 91\%, respectively) with cytosolic APX proteins of Daucus carota (AKH49594) and Spuriopimpinella brachycarpa
(AAF22246). The phylogenetic analysis showed that PgAPX1 and PgAPX2 belong to the cytosolic APX subgroup (Fig. 1a). Consistent with phylogenetic analysis, confocal microscope analysis of PgAPX1 tagging with CFP showed its expression was gained on cytosol which can suggest the cytosol localization of PgAPX1 (Fig. 1c). Up to date, Arabidopsis has total eight types of APXs, consisting three cytosolic APXs, three cytosol membrane-bound APXs, and two chloroplast APXs (Dąbrowska et al. 2007). Some other plants reported have two isoforms of cytosolic APX, such as Oryza sativa L, Capsicum annum, Pinus pinaster, Pissum sativum, Nicotiana tabacum and Spinacia oleraceae (Teixeira et al. 2004). The exact amount of APX family genes present in $P$. ginseng will be known once whole-genome sequencing of ginseng is completed.

MEME analysis found conserved motifs in all plant APX isozymes (Fig. 1b, Supplementary Fig. 2), corresponding to APX's same function in different organelles. The motifs contain the conserved amino acid regions of the APX (Fig. 2a), such as the active site (His 42, Trp 179, Asp 208) (Çelic et al. 2001) and the binding site (His 163) (Lad et al. 2002), which are influential for maintaining the structure (a)

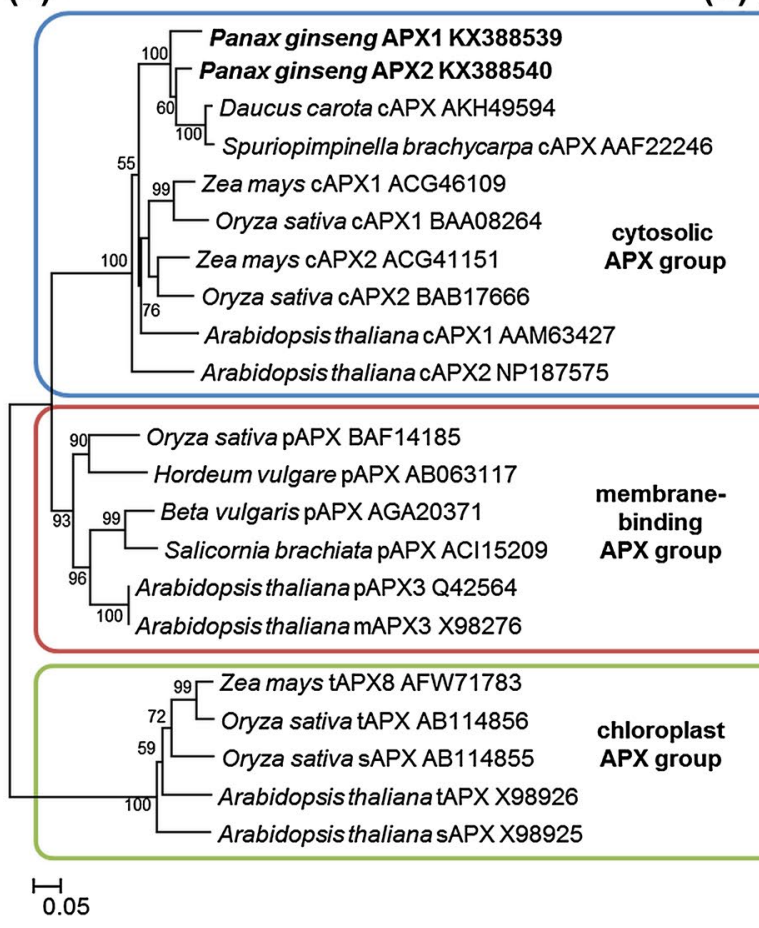

(b) $p$-value Motif location 2.06e-124 $\square \square \square$ $1.74 \mathrm{e}-132 \square \square \square$ $2.38 \mathrm{e}-126 \square \square \square$ $1.64 \mathrm{e}-127 \square \square \square$ $5.33 e-125 \square \square \square$ $1.37 \mathrm{e}-119 \square \square \square$ $5.65 \mathrm{e}-127 \square \square \square$ $1.26 \mathrm{e}-122 \square \square \square$ $4.53 \mathrm{e}-127 \square \square \square$ $3.59 \mathrm{e}-120 \square \square \square$ $1.95 \mathrm{e}-116 \square \square \square$ $1.50 \mathrm{e}-113 \square \square \square$ $7.54 \mathrm{e}-120 \square \square \square$ $2.87 \mathrm{e}-118 \square \square \square$ $1.70 \mathrm{e}-124 \square \square \square$ $1.70 \mathrm{e}-124 \square \square \square$ $1.85 \mathrm{e}-102 \square \square \square \square$ $7.84 \mathrm{e}-102 \square \square \square \square$ $2.44 \mathrm{e}-101 \square \square \square \square$ $9.08 \mathrm{e}-99 \square \square \square \square$ $3.31 \mathrm{e}-98 \square \square \square \square$

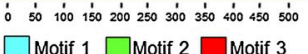

(c)

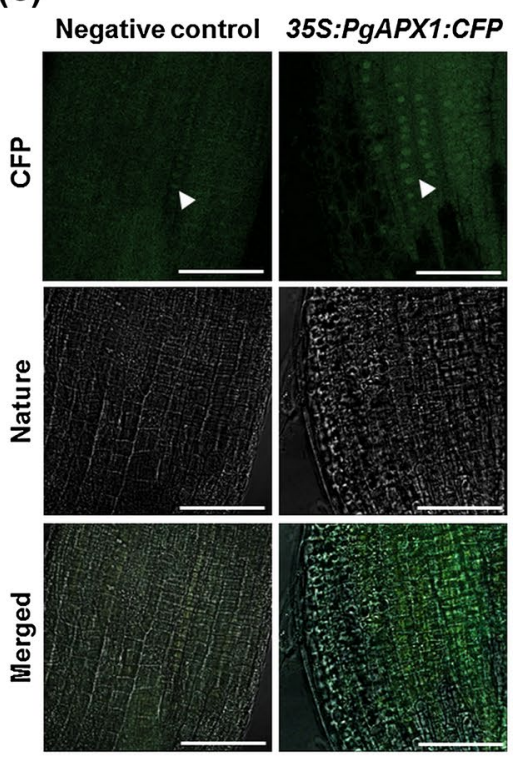

Fig. 1 a Sequence homology analysis of $P g A P X s$ with other $A P X$ genes. The neighbor-joining method was used and the branch lengths are proportional to the divergence, with the scale of 0.05 representing $5 \%$ changes. Protein sequences were from the databases indicated in parentheses. b Organization of putative motifs in APX identified by MEME. Numbered color boxes represent different putative motifs, and the sequences of the motifs are listed in Supplementary Fig. 1.
Motifs 1, 2, and 3 are indicated by the mint, blue, and red boxes, respectively. Motif sizes are indicated at the bottom of the figure. c Confocal microscope photo of $P g A P X 1_{\text {ox }}$ lines (35S:PgAPX1:CFP) tissue indicated PgAPX1 tagged with CFP expressed mainly on cytosol compared to negative control which present some basal expression (indicated from white arrow). Negative control was CaMV promoter fused with CFP (35S::CFP). Scale bar indicates $100 \mu \mathrm{m}$ 
and function of APX (Kjaersgard et al. 1997). Furthermore, amino acid sequence of PgAPX1 and PgAPX2 contained the "GFAEA" motif present in C-terminal of cytosolic APXs (Wu et al. 2014). The hydrophobicity profile similarity of the deduced PgAPX and other nearest cytosolic APX group is shown in Fig. 2b. Both active site (His 42, Trp 179, Asp 208) and binding site (His 163) were found on hydrophobic region. The secondary structure of PgAPXs also showed high resemblance compared with the secondary structure of another close-related plant cytosolic APXs (Supplementary Table 2). The tertiary structure of matured protein of PgAPX1 and PgAPX2 was observed by 3-D modeling and it revealed that all important active sites (His 42, Trp 179, Asp 208) located nearby each other which make space for catalytic reaction (Fig. 2c).

Furthermore, construction of full gene sequence of $P g A P X 1$ and PgAPX2 revealed two genes (2310 and 2843 bp, respectively) consisting nine exons and eight introns (Supplementary Fig. 3), which is typical characteristic of non-chloroplastic APX isoforms, with the exception only for AtAPX (Atlg07890) with eight exons and seven introns (Teixeira et al. 2004). Numerous regulatory elements contributing on stress responsiveness were predicted within $p P g A P X \mathrm{~s}$, such as ethylene-responsive element
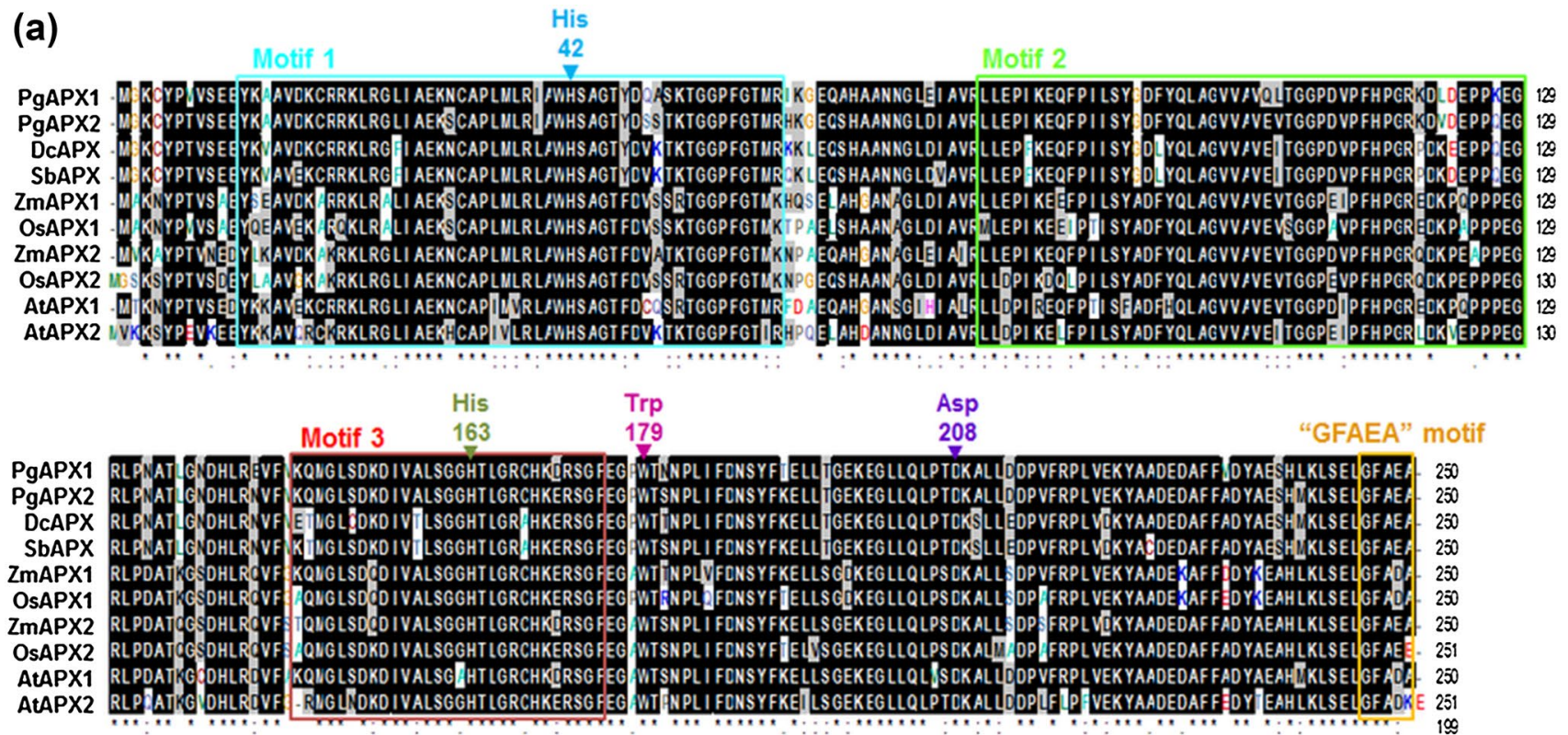

(b)

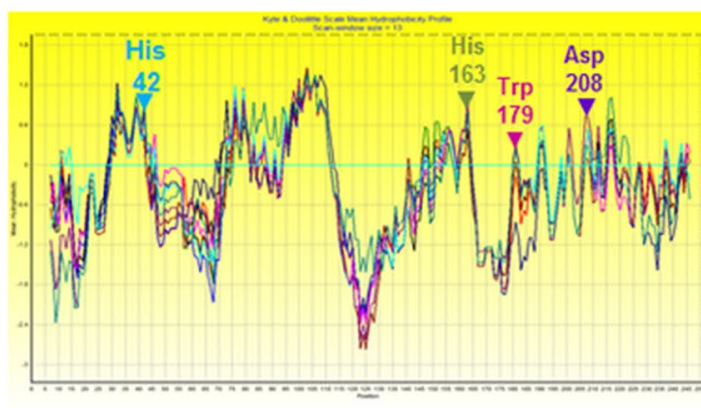

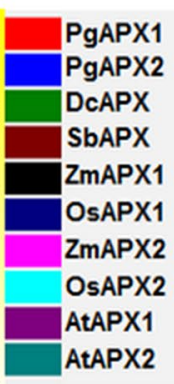

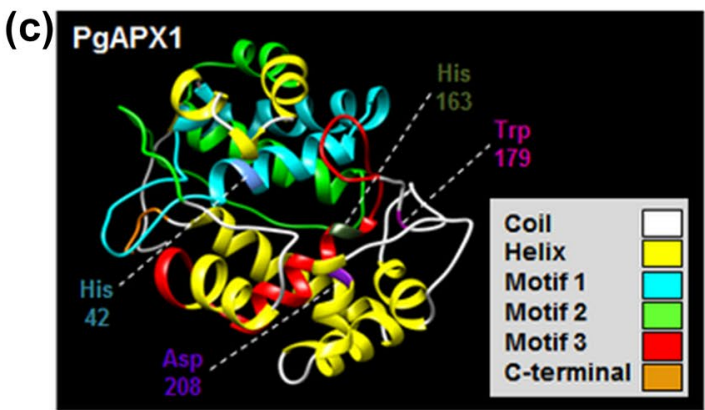

Fig. 2 a Multiple amino acid sequence alignment of PgAPX1 and PgAPX2 with those of proteins encoded Daucus carotal DcAPX (AKH49594), Spuriopimpinella brachycarpa/ SbAPX (AAF22246), Zea mays/ ZmAPX1 (ACG46109); ZmAPX2 (ACG41151), Oryza satival OsAPX1 (BAA08264); OsAPX2 (BAB17666), and Arabidopsis thalianal AtAPX1 (AAM63427); AtAPX2 (NP187575). Asterisks indicate the conserved amino acids residues. The identical and conserved amino acid residues are highlighted with the black and gray background, respectively. Motifs 1,2 , and 3 are indicated by the mint, lime green, and red boxes, respectively. The highly conserved motif "GFAEA" found on C-terminal of cytosolic APXs is indicated by orange color. b Superimposed hydrophobicity profiles and secondary structure predictions for PgAPX group and homologous. Hydrophobic domains are indicated by positive numbers, hydrophilic domains are above the line and hydrophilic domains are below the line. c The predicted 3-D structures of PgAPX1. Comparative representation was performed by UCSF Chimera package and helix and coil structures are depicted as yellow and white, respectively. Motif protein sequences colored the same with the color indicated by MEME. Furthermore, "GFAEA" motif on C-terminal is depicted as an orange color. The presence of the conserved amino acid regions of the APX such as the active site (H42, W179, D208) and the binding site (H163) indicated by blue, magenta, purple and dark green color, respectively 
(ERE), ABA-responsive element (ABRE), MYB-binding motif, and TC-rich repeats (Supplementary Table 3). Previous reports on APX of extreme halophyte, Salicornia brachiata (Tiwari et al. 2013) and Beta vulgaris (DunajskaOrdak et al. 2014), suggest the possibility that $P g A P X$ s can be expressed under broad kind of stresses. Notwithstanding,

\section{Tissue expression analysis of PgAPX genes}

$P g A P X$ transcription profile was examined in different ginseng tissues using real-time PCR. PgAPXl was highly expressed in the stem and leaf, compared to the root, whereas the highest expression level of $P g A P X 2$ was detected in the leaf (Supplementary Fig. 4a). Overall, most abundant transcript of $P g A P X$ was found in leaf tissues although it was detectable in all tested tissues. This result is similar to the recent review in which $A P X$ gene was expressed in almost all analyzed tissues of Arabidopsis with various folds (Ozyigit et al. 2016). Cytosolic AtAPX1 (Atlg07890) showed higher expression significantly at roots particularly at its growing zone, while other cytosolic APX isoform, AtAPX6 (At4g32320) were expressed mainly in leaf (Ozyigit et al. 2016). In Solanum tuberosum L., the cytosolic $A P X$ transcript was observed at the same level in leaves, shoots, and sprouts (da Costa et al. 2006). Histochemical assay of $p P g A P X 1: \because G U S$ and $p P g A P X 2:: G U S$ construct in transgenic Arabidopsis showed that both $p P g A P X 1$ and $p P g A P X 2$ expression initiated from roots four days after sprout (Figs. 3a, 4 DAS), gradually moved into stems (Fig. 3a, 6 DAS), highly expressed in leaves and barely found in roots of one-week-old seedlings (Fig. 3a, 8 DAS and 10 DAS), and again highly accumulated in stem of two-week-old Arabidopsisseedlings (Fig. 3a, 14 DAS). The various change of $p P g A P X \mathrm{~s}: G U S$ expression during the seedling growth indicated that the expression of $A P X$ genes was induced in a tissue-dependent way (Ozyigit et al. 2016).

\section{Temporal expression of PgAPX 1 and PgAPX2 gene in response to salt stresses}

$P g A P X$ expression pattern at several time points was checked in two-year-old $P$. ginseng treated with $200 \mathrm{mM}$ $\mathrm{NaCl}$ using real-time PCR (Fig. 3b). Contrary with $P g A P X 2, \quad P g A P X 1$ expression level was up-regulated quickly at $12 \mathrm{~h}$ and gained its maximum level at $24 \mathrm{~h}$ post-treatment. Meanwhile, $P g A P X 2$ expression was not significant until $24 \mathrm{~h}$ post treatment. Both $P g A P X 1$ and $P g A P X 2$ expression levels decreased at $48 \mathrm{~h}$ post treatment. Similarly, the expression of APX genes from other species is upregulated during salt stress (Sun et al. 2010; Liu et al. 2014; Singh et al. 2014). On 200-300 mM NaCl treatment, histochemical assay of $p P g A P X 1:: G U S$ and pPgAPX2::GUS showed that both $P g A P X 1$ and $P g A P X 2$ promoter expression can be driven by salt stress (Supplementary Fig. 4b). However, $p P g A P X 1$ seems to have (a)

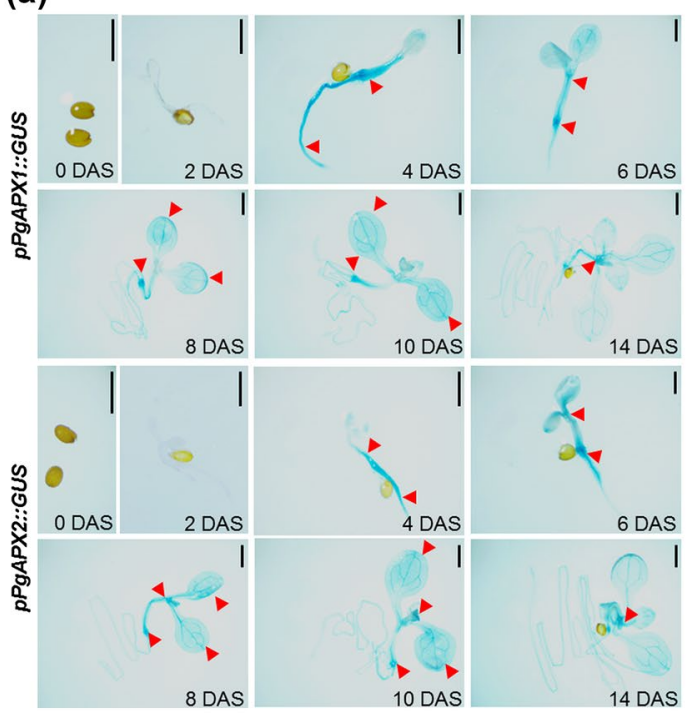

(b)

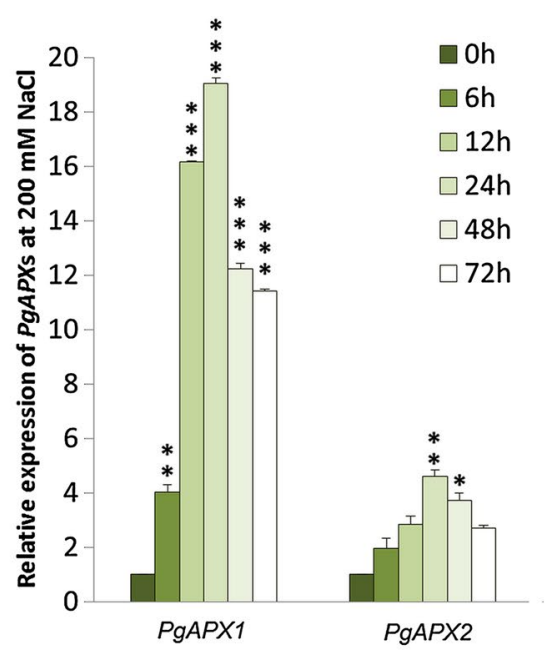

Fig. 3 a Histochemical analysis of transgenic Arabidopsis line harboring $p P g A P X 1:: G U S$ and $p P g A P X 2:: G U S$ on various developmental stages. The red arrows indicate the concentrated and flow change of GUS expression. For histochemical analysis, 5 biological replicates were used for each treatment. Scale bar indicates $5 \mathrm{~mm}$. b A relative expression of $P g A P X 1$ and $P g A P X 2$ of two-year-old gin- seng at various time point of $200 \mathrm{mM} \mathrm{NaCl}$ post-treatment. Bars indicate the mean value $\pm \mathrm{SE}$ from three independent experiments. The actin housekeeping gene of ginseng was selected as an internal control. Means of three independent replicates are statistically analyzed and compared with $0 \mathrm{~h}$ sample, by using Student's $t$ test $\left({ }^{*} p<0.05\right.$, ${ }^{* *} p<0.01, * * * p<0.001$ ) 

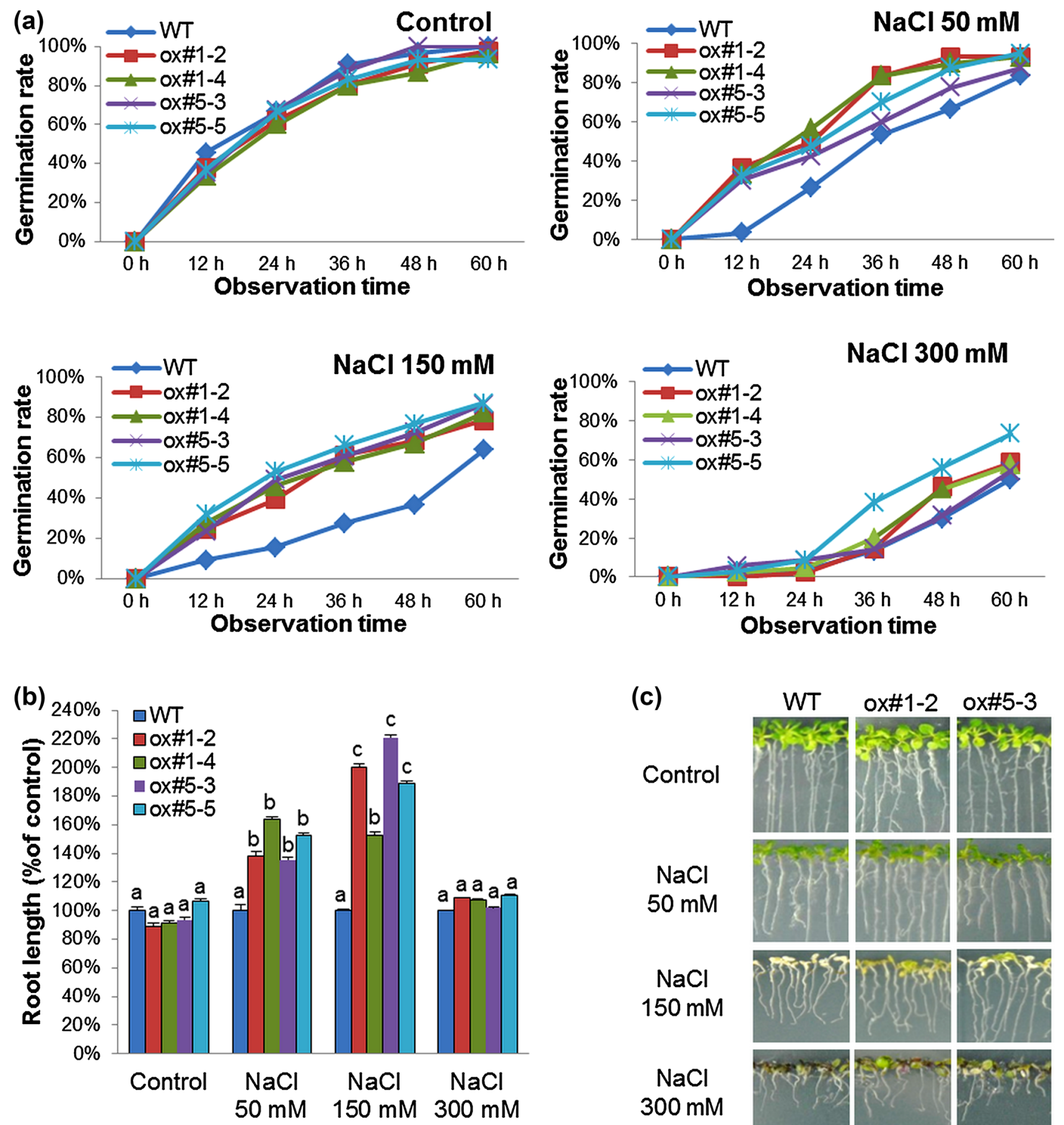

(c)

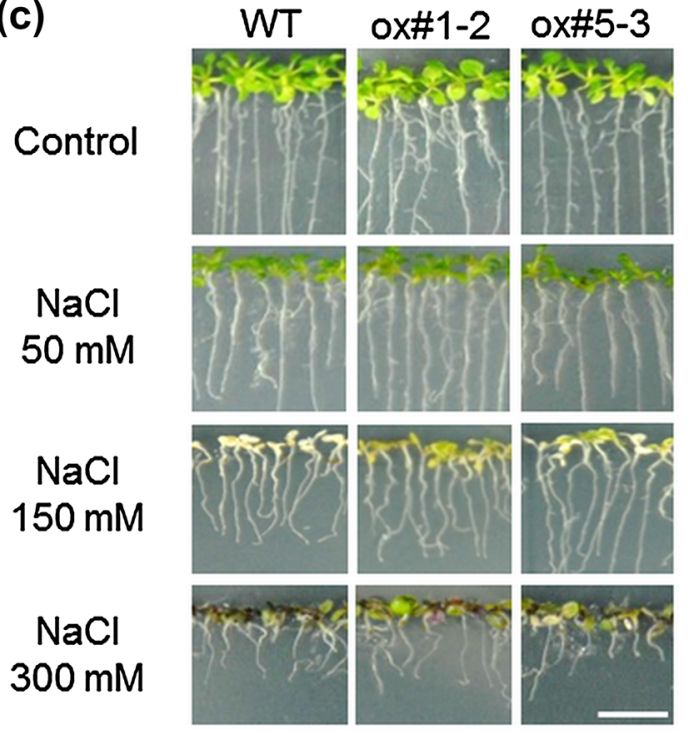

Fig. 4 a Germination rate and $\mathbf{b}$ root length of $P g A P X 1_{o x}$ lines on $A$. thaliana under salt stress. Different letters on top of the bars indicate significant difference at a level of $p<0.05$, as determined by Duncan's multiple range test (DMRT). The graphical value represents the mean value of 3 independent replicates, consists of 100 seeds/ seed-

stronger expression compared to $p P g A P X 2$ (Supplementary Fig. 4b). Not only responded to the salt stress, $P g A P X I$ promoter was also expressed strongly under peroxide $\left(10 \mathrm{mM} \mathrm{H} \mathrm{H}_{2} \mathrm{O}_{2}\right)$, heat $\left(37^{\circ} \mathrm{C}\right)$ and cold $\left(4^{\circ} \mathrm{C}\right)$ treatment lings for each treatment. c Morphological observation of WT and various $P g A P X 1_{\text {ox }}$ lines on $1 / 2 \mathrm{MS}$ with various concentration of $\mathrm{NaCl}$. The root length measurement and seedlings morphology documentation were taken at 16-day-old seedlings stage. Scale bar indicates $1 \mathrm{~cm}$

(Supplementary Fig. 5a), indicating its induction by broad abiotic stresses. Our result corresponds with the previous study that $P g A P X$ was up-regulated under abiotic stresses including peroxide, heat, and cold treatment but slight 
down-regulation or no significant change of transcript level during pathogen attack (Sathiyaraj et al. 2011) using same PgAPX1 qRT-PCR primer (Supplementary Fig. 1). Thus, PgAPXI was chosen to be constructed with CaMV promoter, transformed into A. thaliana, screened with $50 \mu \mathrm{g} /$ $\mathrm{mL}$ hygromycin and finally the successful transgenic plants were detected by PCR. PgAPX1 \#5-5 transgenic lines were selected for further analysis.

\section{Stress tolerance in PgAPX $1_{o x}$ A rabidopsis}

It has been reported that the overexpression of APX is essential for the effective protection of plants against oxidative damage caused by salt stress (Diaz-Vivancos et al. 2013a). To examine whether overexpression of $P g A P X$ in Arabidopsis can improve salt tolerance, germination ratio was counted in $1 / 2 \mathrm{MS}$ medium containing different levels of $\mathrm{NaCl}$. No clear differences were observed between WT and $P g A P X 1_{\text {ox }}$ lines for $60 \mathrm{~h}$ after sowing at normal media (Fig. 4a). However, $P g A P X 1_{\text {ox }}$ lines showed higher germination rate compared to WT under $150 \mathrm{mM} \mathrm{NaCl}$ (15-23\% higher) at $60 \mathrm{~h}$. At $300 \mathrm{mM} \mathrm{NaCl}$ condition, only $P g A P X_{\text {ox }} \# 5-5$ showed higher germination rate compared to WT (23.5\% higher). Other treatment results for germination rate of $P g A P X 1_{\text {ox }}$ lines under heat $\left(37^{\circ} \mathrm{C}\right)$ and cold $\left(4^{\circ} \mathrm{C}\right)$ was either slightly significant or not significant (Supplementary Fig. 5b). In the case of root growth assay, four-day-old germinated seedlings were moved into $1 / 2 \mathrm{MS}$ with various $\mathrm{NaCl}$ concentrations. After 12 days, no visual differences in root growth and leaves color were observed between WT and $P g A P X 1_{\text {ox }}$ lines under non-salt stress condition (Fig. 4b, c). However, during $50 \mathrm{mM} \mathrm{NaCl}$ treatment, the growth of WT plants was slightly inhibited compared with those of $P g A P X 1_{\text {ox }}$ seedlings after 12 days, as shown shorter than transgenic lines (Fig. $4 b, c)$. Once $150 \mathrm{mM} \mathrm{NaCl}$ was given to plants for 12 days, the WT seedlings simply ceased growth and their leaves turned white, whereas the transgenic plants merely grew slowly and their leaves stayed green (Fig. 4b, c). All transgenic lines and WT showed similarly stunted and ceased seedlings under $300 \mathrm{mM} \mathrm{NaCl}$ condition at 12 days (Fig. 4c). Overall, growth of all tested lines was suppressed to different degrees under salt stress, although the $P g A P X 1_{\text {ox }}$ lines showed higher tolerance to $\mathrm{NaCl}$ at the seedling stage, which confirmed by higher germination rate and longer roots (Fig. 4). This was concurrent with previous reports of transgenic plants overexpressing the pepper APX (Sarowar et al. 2005), rice $A P X$ (Lu et al. 2007) and Lycium chinense $A P X$ genes (Wu et al. 2014).

Moreover, to validate the function of the $P g A P X I$ gene during salt stress, three-week-old Arabidopsis plants (on pot) were watered with or without $200 \mathrm{mM} \mathrm{NaCl}$ solution. All plants watered with $\mathrm{NaCl}$ solution displayed a common growth inhibition. Compared with more obvious yellow leaves of the WT plants (Fig. 5a), the $P g A P X 1_{\text {ox }}$ grew as normal, and apparently, a slight number of leaves suffered damage. These symptoms indicated that overexpression of the $P g A P X 1$ gene conferred a high tolerance to salt stress in transgenic Arabidopsis plants. Oxidative damage marked by the accumulation of ROS such as $\mathrm{H}_{2} \mathrm{O}_{2}$ when plants were subjected to salt stress (Hasegawa et al. 2000). Salt stress can trigger $\mathrm{H}_{2} \mathrm{O}_{2}$ accumulation as reported in rice, marine macroalgae, and Medicago sativa (Luo and Liu 2011; Hu et al. 2012; Mishra et al. 2013; Guo et al. 2014). The $\mathrm{H}_{2} \mathrm{O}_{2}$ level was high on WT plant under $200 \mathrm{mM} \mathrm{NaCl}$ treatment, indicated by intense brown color after DAB staining (Fig. 5b). Meanwhile, all $P g A P X l_{\text {ox }}$ lines showed slight or much less brown color after staining. These results indicated that transgenic lines have less level of $\mathrm{H}_{2} \mathrm{O}_{2}$ accumulation in response to salt stress, compared to WT plant.

\section{Transcription pattern analysis of $\mathrm{PgAPX} 1_{\mathrm{ox}}$ lines under salt stress}

$\Delta$ 1-Pyrroline-5-carboxylate synthetase (P5CS) is the rate-limiting enzyme which catalyzing proline biosynthesis (Yoshiba et al. 1999). It was reported that P5CS1 but not P5CS2 gene is required for proline accumulation during stress condition in A. thaliana (Székely et al. 2008). Higher proline content can be found on $P g A P X 1_{\text {ox }}$ lines, which was along with higher transcript level of AtP5CS1 (Fig. 5c). Similar study reported that induction of AtP5CS1 expression during salt stress can be depend on abscisic acid (ABA) and phospholipase C (Abraham et al. 2003; Parre et al. 2007).

The transcription pattern of several ROS-related genes was analyzed from leaf samples of WT and $P g A P X$ $1_{\mathrm{ox}}$ Arabidopsis at 5 days post treatment of $200 \mathrm{mM} \mathrm{NaCl}$, which showed the distinct result of morphological appearance and DAB staining. PgAPXI transcript level was found significantly high in all selected $P g A P X 1_{\text {ox }}$ lines (Fig. 5c). Transcription level of AtSODl was found to be significantly increased, although expression of AtAPXI, AtAPX2, AtCAT1, AtGPX1, and AtPrxR1 was found as high as WT (Fig. 5c, Supplementary Fig. 6). Gupta et al. (1993) described that overexpression of SOD on pea, not only exhibited SOD transcript and enzyme activity, but also increase level of APX mRNA and enzyme activity. Resembling to this study, overexpression of $S O D$ and $A P X$ in plum (Diaz-Vivancos et al. 2013b) and sweet potato (Yan et al. 2016) increased their salt stress tolerance. In this study, increasing levels of $P g A P X 1$ and AtSODI can clearly lead to enhanced oxidative protection in plants, as showed by lowering $\mathrm{H}_{2} \mathrm{O}_{2}$ content in $P g A P X I_{\text {ox }}$ lines (Fig. 5b) due to higher respective enzyme activity (Fig. $5 \mathrm{~g}-\mathrm{h}$ ). Enhanced antioxidant defense system can improve salt tolerance in 


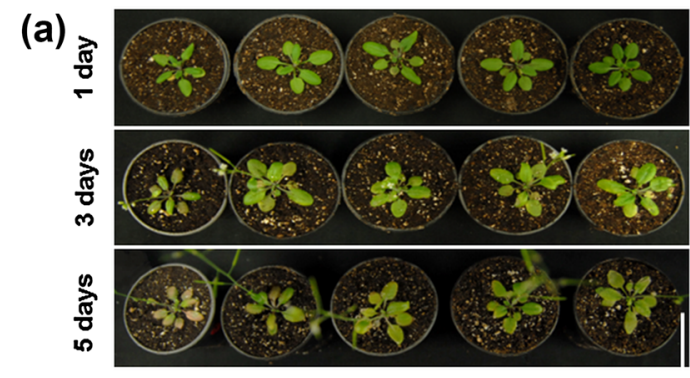

(b)

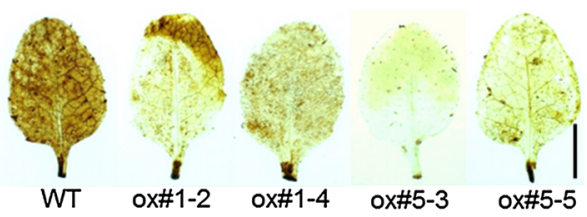

(d)

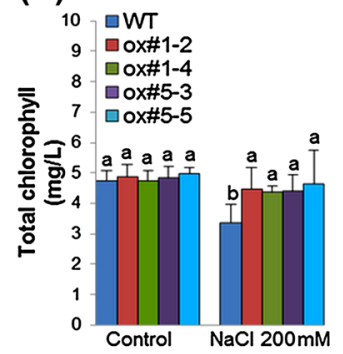

(e)

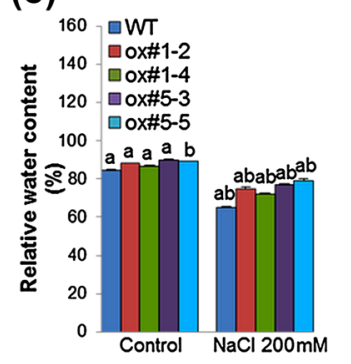

(c)

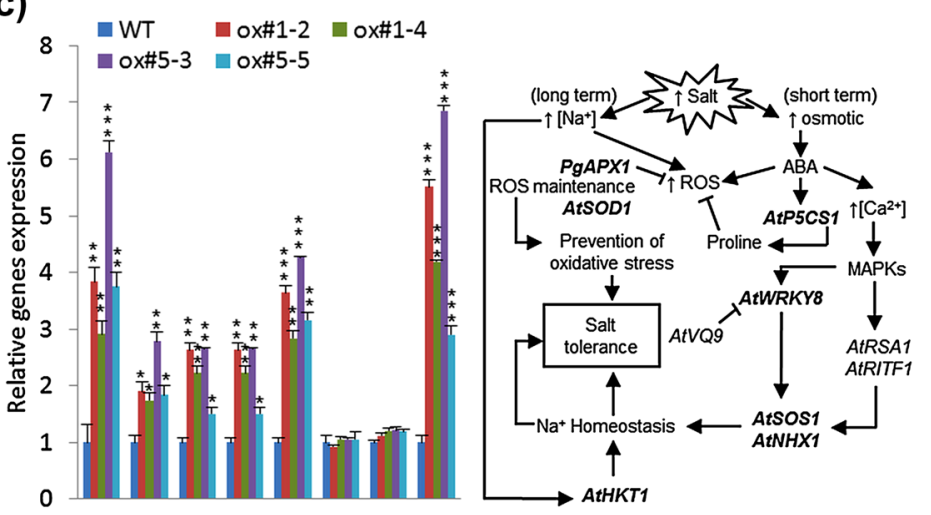

(f)

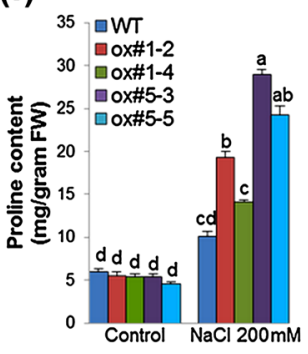

(g)

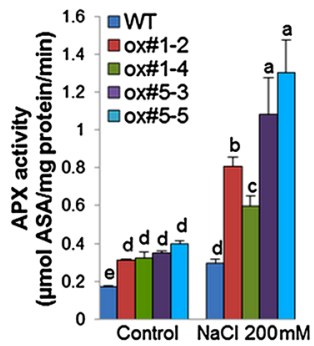

(h)

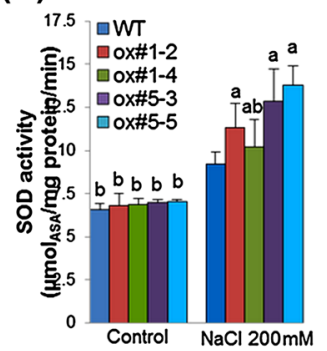

Fig. 5 a Visual symptoms on representative WT plants (WT) transgenic Arabidopsis plants overexpressing $P g A P X 1$ after $200 \mathrm{mM} \mathrm{NaCl}$ treatment (Scale bar indicated $2 \mathrm{~cm}$ ) and $\mathbf{b} \mathrm{H}_{2} \mathrm{O}_{2}$ visualization (DAB staining) of $P g A P X 1_{\text {ox }}$ lines after 5 days $200 \mathrm{mM} \mathrm{NaCl}$ treatment (Scale bar indicated $3 \mathrm{~mm}$ ). For DAB staining analysis, 5 biological replicates were used for each treatment. $\mathbf{c}$ The transcript levels of $P g A P X 1$ and other genes in different overexpressed lines were analyzed by qRT-PCR. Total RNA was extracted from leaf samples collected from three-week-old T2 transgenic plants after 5 days $200 \mathrm{mM}$ $\mathrm{NaCl}$ treatment. The actin housekeeping gene of Arabidopsis was selected as an internal control. Means of three independent replicates are statistically analyzed and compared with control at $(* p<0.05$,
$* * p<0.01, * * * p<0.001)$ using Student's t-test. A suggested schematic model of overexpressing PgAPXI effect on Arabidopsis salt stress defense pathway also provided. The solid line indicates activating/ increasing while the broken line indicates deactivating/ inhibiting. The bold font indicates its mRNA expression was found to be upregulated significantly. $\mathbf{d}-\mathbf{h}$ Biochemical analysis of three-week-old $P g A P X 1_{\text {ox }}$ lines after 5 days salt stress $(200 \mathrm{mM})$ : d Total chlorophyll, e Relative water content, f Proline content, g APX activity and h SOD activity. Different letters on top of the bars indicate significant difference at a level of $p<0.05$, as determined by Duncan's multiple range test
$P g A P X 1_{\text {ox }}$ lines. Probably, $S O D$ and $A P X$ genes regulation was linked through $\mathrm{H}_{2} \mathrm{O}_{2}$ signaling. ROS generated during salt stress get converted into $\mathrm{H}_{2} \mathrm{O}_{2}$ by SOD and its optimum level was maintained by APX, as reported by Shafi et al. (2015).

AtWRKY8 (At5g46350) expression was higher in $P g A P X 1_{\text {ox }}$ lines compared to WT, while the expression of AtVQ9 (Atlg78310) was not altered (Supplementary Fig. 6). Previous review article stated that AtWRKY8 regulate signaling cascades in salinity, drought, and oxidative stresses by binding to W-box of downstream genes related to stress response (Banerjee and Roychoudhury 2015). AtWRKY 8 was primarily reacting to high salinity and only specifically interacted with $A t V Q 9$, in which its interaction decreased the DNA-binding activity of AtWRKY8. In wrky 8 mutants, the expression of Salt Overly Sensitive genes (SOS1, SOS2, and SOS3) were reduced but increased in $v q 9$ mutants under salt treatment (Banerjee and Roychoudhury 2015). SOS1 is plasma membrane $\mathrm{Na}^{+} / \mathrm{H}^{+}$antiporter which acts crucially in $\mathrm{Na}^{+}$exclusion by the driving force produced by plasma membrane $\mathrm{H}^{+}$-ATPase (Shi et al. 2000). Similarly, the vacuolar $\mathrm{Na}^{+} / \mathrm{H}^{+}$exchanger (NHX1) helps pushing excess $\mathrm{Na}^{+}$ions into vacuoles (Ulrich et al. 2014). Three key components of SOS pathway includes SOS1; SOS2, a serine/threonine protein kinase (Liu et al. 2000) and SOS3, a Ca ${ }^{2+}$ sensor (Liu and Zhu 1998). SOS2SOS3 kinase complex regulates SOS1 activity by phosphorylation-mediated regulation (Sanchez-Barrena et al. 2005). The histidine kinase transporter (HKT) is a low-affinity $\mathrm{Na}^{+}$ion transporter, which assist the removal of $\mathrm{Na}^{+}$from xylem sap into surrounding parenchyma cells (Davenport et al. 2007). Meanwhile, nucleus-localized AtVQ9 
protein mainly expressed in roots and salt stress tolerance was enhanced by its mutation. It was proved that $A t V Q 9$ acts antagonistically with AtWRKY8 to mediate salt stress responses by maintaining ion homeostasis, especially at a lower cytosolic $\mathrm{Na}^{+} / \mathrm{K}^{+}$ratio (Hu et al. 2013). As a transcription factor, expression of AtWRKY8 is known to be regulated by MAPK (mitogen-activated protein kinases)mediated phosphorylation, especially calcium-dependent protein kinases (CPDKs), which can promote its DNA binding activity (Tsuda and Somssich 2015). ABA signaling generates ROS and $\mathrm{Ca}^{2+}$ signals that activates CPDK. In the present study, similar increasing expression pattern was found for AtWRKY8, AtHKT1, AtNHXI, and AtSOS1 (Fig. 5c, Supplementary Fig. 6); indicating that the cells tried to pump out excess $\mathrm{Na}^{+}$or distribute it to other cells to prevent the $\mathrm{Na}^{+}$toxicity (Ulrich et al. 2014).

Furthermore, AtRSA1 (Short Root in SAlt medium 1; At3g06590), the nuclear-localized calcium-binding protein, senses salt-induced changes in nuclear free calcium and interacts with RITF1 (RSA1 Interacting Transcription Factor 1, a bHLH transcription factor), which may be phosphorylated by nuclear-localized MAPKs. The RSA1RITF1 complex maintains expression of genes involved in detoxification of salt-induced ROS and $\mathrm{Na}^{+}$homeostasis during salt stress (Guan et al. 2013). However, the expression of AtRSAl and AtRITFl were similar between WT and $P g A P X 1_{\text {ox }}$ lines. These results suggested that probably AtWRKY8 induced AtSOSI directly or indirectly in a separate way that AtRSAl and AtRITF1 did. Probably, different MAPKs are responsible for each of these pathways. The high expression level of transcription factor AtWRKY 8 and stable expression of its antagonist, $A t V Q 9$ in $P g A P X 1_{\text {ox }}$ lines suggested that probably MAPK triggered WRKY protein and later induced SOS1 due to lower ROS content. Higher $\mathrm{H}_{2} \mathrm{O}_{2}$ scavenging activity of both PgAPX1 and AtSOD1 were probably involved to lower ROS level.

In summary, salt stress treatment generated ROS production which induced expression of antioxidant genes such as $A t A P X 1$ and $P g A P X 1$. However, the expression of $P g A P X 1$ was only found higher in $P g A P X 1_{\text {ox }}$ lines, compared to WT. Overexpression of $P g A P X 1$ upregulated transcription factor AtWRKY8 but not its antagonist, AtVQ9. These phenomena probably affected AtSOSI directly or indirectly which also found to be upregulated in $P g A P X 1_{\text {ox }}$ lines.

\section{Biochemical analysis of $\mathrm{PgAPX} 1_{\mathrm{ox}}$ lines under salt stress}

Next, some biochemical analysis such as total chlorophyll content, RWC, proline content and APX activity were assayed before (0th day) and after (5th day) the exposure of $200 \mathrm{mM} \mathrm{NaCl}$. Without the $\mathrm{NaCl}$ treatment, total chlorophyll content was same in WT and $P g A P X I_{\text {ox }}$ lines (Fig. 5d). During salt stress, total chlorophyll content of all tested lines was decreased, but the extent of this decline in $P g A P X 1_{\text {ox }}$ was not significant and much less than that in the WT plants (Fig. 5d). These results indicated that the $P g A P X 1_{\text {ox }}$ were less suppressed in growth and they lost less chlorophyll than the WT seedlings. Both WT and $P g A P X 1_{\text {ox }}$ have similar RWC under control condition. However, WT suffered a significant RWC decline during salt stress as compared to $P g A P X 1_{\text {ox }}$ lines (Fig. 5e). To relieve the harmful effects of salinity, one of the strategies for plants is to produce more small osmolytes or stress proteins (Zhu 2001). Increased level of proline was observed in transgenic lines under salt stress condition. Proline acts as a stabilizer of the plasma membrane and free radical scavenger, which can protect the plant under stress conditions (Jain et al. 2001). The accumulation of proline was 1.5-3 folds higher in transgenic lines as compared to WT under the salt stress (Fig. 5f). Results in this study suggest that increased proline content under salt stress might have helped plants to avoid the osmotic effect of high salinity. The free proline was used as an osmoprotectant which could help plants to adjust their cellular osmotic potential as well as act as an antioxidant (Verbruggen and Hermans 2008). These results ensure the histochemical assay of $P g A P X 1_{\text {ox }}$ lines (Fig. 5b) which showed lower $\mathrm{H}_{2} \mathrm{O}_{2}$ accumulation in leaves after $200 \mathrm{mM} \mathrm{NaCl}$ treatment. To test whether APX activity affected $\mathrm{H}_{2} \mathrm{O}_{2}$ levels, APX activity was compared between WT and $P g A P X 1_{\text {ox }}$ plants before and after salt treatment. As shown in Fig. $5 \mathrm{~g}-\mathrm{h}$, the APX and SOD enzyme activity of all tested transgenic lines were significantly higher than WT plants under normal condition and salt stress conditions, respectively. These outcomes indicated that greater APX and SOD activity by $P g A P X 1$ overexpression plays an effective role in alleviating the adverse stress effects on Arabidopsis growth and development.

In summary, two full-length of $P$. ginseng cDNA encoding APX were identified, and the gene structures were demonstrated. Their expression pattern was analyzed in various ginseng tissues and under salt stresses condition. Phylogenetic comparison with other plants APX group and bioinformatics analysis revealed that both PgAPX1 and PgAPX2 belong to cytosolic APX members in P. ginseng. Arabidopsis overexpressing PgAPXI demonstrated enhanced tolerance against $300 \mathrm{mM} \mathrm{NaCl}$ by displaying higher germination rate, longer roots, less leaf chlorosis, less $\mathrm{H}_{2} \mathrm{O}_{2}$ accumulation, and higher chlorophyll content, relative water content, and proline content under salt stress than WT plants, caused by higher $P g A P X 1$ expression and APX activity. Our results suggest $P g A P X I$ can help plant to be more tolerant of salt stress by affecting the ion homeostasis regulation and ROS detoxification regulation. This is the first report describing the isolation of APX genes from $P$. ginseng and it provides significant information for 
improving abiotic stress tolerance by genetically engineering of crop/ other plants.

Acknowledgements This research was supported by a grant from the Basic Science Research Program through the National Research Foundation (NRF) funded by the Ministry of Education (2016R1A6A3A11931858), Republic of Korea (YJ Kim), as well as an iPET grant (112142-05-4-SB010) from the Korea Institute of Planning and Evaluation for Technology in Food, Agriculture, Forestry and Fisheries, Republic of Korea (DC Yang).

\section{Compliance with ethical standards}

Conflict of interest The authors declare that they have no conflict of interest.

\section{References}

Abraham E, Rigo G, Szekely G, Nagy R, Koncz C, Szabados L (2003) Light-dependent induction of proline biosynthesis by abscisic acid and salt stress is inhibited by brassinosteroid in Arabidopsis. Plant Mol Biol 51:363-372

Agrawal GK, Jwa NS, Iwahashi H, Rakwal R (2003) Importance of ascorbate peroxidases $O S A P X 1$ and $O S A P X 2$ in the rice pathogen response pathways and growth and reproduction revealed by their transcriptional profiling. Gene 322:93-103

Apel K, Hirt H (2004) Reactive oxygen species: metabolism, oxidative stress, and signal transduction. Annu Rev Plant Biol 55:373-399

Ara N, Nakkanong K, Lv W, Yang J, Hu Z, Zhang M (2013) Antioxidant enzymatic activities and gene expression associated with heat tolerance in the stems and roots of two cucurbit species ("Cucurbita maxima" and "Cucurbita moschata") and their interspecific inbred line "Maxchata". Int J Mol Sci 14:24008-24028

Arnold K, Bordoli L, Kopp J, Schwede T (2006) The SWISSMODEL workspace: a web-based environment for protein structure homology modeling. Bioinformatics 22:195-201

Asada K (1992) Ascorbate peroxidase-A hydrogen peroxide scavenging enzyme in plants. Physiol Plant 85:235-241

Ashraf M, Foolad MR (2013) Crop breeding for salt tolerance in the era of molecular markers and marker-assisted selection. Plant Breed 132:10-20

Badawi GH, Kawano N, Yamauchi Y, Shimada E, Sasaki R, Kubo A, Tanaka K (2004) Over-expression of ascorbate peroxidase in tobacco chloroplasts enhances the tolerance to salt stress and water deficit. Physiol Plant 121(2):231-238

Bailey TL, Boden M, Buske FA, Frith M, Grant CE, Clementi L, Ren J, Li WW, Noble WS (2009) MEME SUITE : tools for motif discovery and searching. Nuc Acids Res 37: 202-208

Banerjee A, Roychoudhury A (2015) WRKY proteins: signaling and regulation of expression during abiotic stress responses. Sci World J Article ID 807560, 1-17, 10.1155/2015/807560

Blokhina O, Virolainen E, Fagerstedt KV (2003) Antioxidants, oxidative damage and oxygen deprivation stress. Ann Bot 91:179-194

Bonifacio A, Martins MO, Ribeiro CW, Fontenele AV, Carvalho FE, Margis-Pinheiro M, Silveira JA (2011) Role of peroxidases in the compensation of cytosolic ascorbate peroxidase knockdown in rice plants under abiotic stress. Plant Cell Environ 34:1705-1722

Carillo P, Mastrolonardo G, Nacca F, Parisi D, Verlotta A, Fuggi A (2008) Nitrogen metabolism in durum wheat under salinity: accumulation of proline and glycine betaine. Funct Plant Biol $35: 412-426$
Carmody M, Crisp PA, d'Alessandro S, Ganguly D, Gordon M, Havaux M, Albrecht-Borth V, Pogson BJ (2016) Uncoupling high light responses from singlet oxygen retrograde signaling and spatial-temporal systemic acquired acclimation in Arabidopsis. Plant Physiol 171:1734-1749

Çelic A, Cullis P, Sutcliffe M, Sangar R, Raven E (2001) Engineering the active site of ascorbate peroxidase. Eur J Biochem 268:78-85

Chung IM, Lim JJ, Ahn MS, Jeong HN, An TJ, Kim SH (2016) Comparative phenolic compound profiles and antioxidative activity of the fruit, leaves, and roots of Korean ginseng (Panax ginseng Meyer) according to cultivation years. J Ginseng Res 40(1):68-75

Clough SJ, Bent AF (1998) Floral dip: a simplified method for Agrobacterium-mediated transformation of Arabidopsis thaliana. Plant J 16(6):735-743

D’Arcy-Lameta A, Ferrari-Iliou R, Contour-Ansel D, Pham-Thi AT, Zuily-Fodil Y (2006) Isolation and characterization of four ascorbate peroxidase cDNAs responsive to water deficit in cowpea leaves. Ann Bot 97:133-140

da Costa DS, Pereira CS, Teixeira J, Pereira S (2006) Isolation and characterisation of a cDNA encoding a novel cytosolic ascorbate peroxidase from potato plants (Solanum tuberosum L.). Acta. Physiol Plant 28(1):41-47

Dąbrowska GR, Kata AL, Goc A, Szechyńska-Hebda MA, Skrzypek ED (2007) Characteristics of the plant ascorbate peroxidase family. Acta Biol Cracow Ser Bot 49:7-17

Daudi A, Cheng Z, O'Brien JA, Mammarella N, Khan S, Ausubel FM, Bolwell GP (2012) The apoplastic oxidative burst peroxidase in Arabidopsis is a major component of pattern-triggered immunity. Plant Cell 24(1):275-287

Davenport RJ, Muñoz-Mayor AL, Jha D, Essah PA, Rus AN, Tester M (2007) The $\mathrm{Na}^{+}$transporter AtHKT1; 1 controls retrieval of $\mathrm{Na}^{+}$from the xylem in Arabidopsis. Plant Cell Environ 30(4):497-507

Davletova S, Rizhsky L, Liang H, Shengqiang Z, Oliver DJ, Coutu J, Shulaev V, Schlauch K, Mittler R (2005) Cytosolic ascorbate peroxidase 1 is a central component of the reactive oxygen gene network of Arabidopsis. Plant Cell 17:268-281

Diaz-Vivancos P, Barba-Espin G, Hernandez JA (2013a) Elucidating hormonal/ROS networks during seed germination: insights and perspectives. Plant Cell Rep 32:1491-1502

Diaz-Vivancos P, Faize M, Barba-Espin G, Faize L, Petri C, Hernández JA, Burgos L (2013b) Ectopic expression of cytosolic superoxide dismutase and ascorbate peroxidase leads to salt stress tolerance in transgenic plums. Plant Biotech J 11(8):976-985

Dietz KJ, Mittler R, Noctor G (2016) Recent progress in understanding the role of reactive oxygen species in plant cell signaling. Plant Physiol 171(3):1535-1539

Dunajska-Ordak K, Skorupa-Kłaput M, Kurnik K, Tretyn A, Tyburski J (2014) Cloning and expression analysis of a gene encoding for ascorbate peroxidase and responsive to salt stress in beet (Beta vulgaris). Plant Mol Biol Rep 32(1):162-175

Fryer MJ, Ball L, Oxborough K, Karpinski S, Mullineaux PM, Baker NR (2003) Control of Ascorbate Peroxidase 2 expression by hydrogen peroxide and leaf water status during excess light stress reveals a functional organisation of Arabidopsis leaves. Plant $\mathrm{J}$ 33:691-705

Gasteiger E, Hoogland C, Gattiker A, Duvaud S, Wilkins MR, Appel RD, Bairoch A (2005) Protein identification and analysis tools on the ExPASy server. In: John M. Walker (ed): The Proteomics protocols handbook. Humana Press, New York pp 571-607

Geourjon C, Deleage G (1995) SOPMA: significant improvements in protein secondary structure prediction by consensus prediction from multiple alignments. Comput Appl Biosci 11(6):681-684 
Guan Q, Wu J, Yue X, Zhang Y, Zhu J (2013) A nuclear calciumsensing pathway is critical for gene regulation and salt stress tolerance in Arabidopsis. PLoS Genet 9(8):1-16

Guo Z, Tan J, Zhuo C, Wang C, Xiang B, Wang Z (2014) Abscisic acid, $\mathrm{H}_{2} \mathrm{O}_{2}$ and nitric oxide interactions mediated cold-induced S-adenosylmethionine synthetase in Medicago sativa subsp. falcata that confers cold tolerance through up-regulating polyamine oxidation. Plant Biotechnol J 12:601-612

Gupta AS, Webb RP, Holaday AS, Allen RD (1993) Overexpression of superoxide dismutase protects plants from oxidative stress (induction of ascorbate peroxidase in superoxide dismutase-overexpressing plants). Plant Physiol 103(4):1067-1073

Hasegawa PM, Bressan RA, Zhu JK, Bohnert HJ (2000) Plant cellular and molecular responses to high salinity. Ann Rev Plant Biol 51(1):463-499

Hu L, Li H, Pang H, Fu J (2012) Responses of antioxidant gene, protein and enzymes to salinity stress in two genotypes of perennial ryegrass (Lolium perenne) differing in salt tolerance. J Plant Physiol 169:146-156

Hu Y, Chen L, Wang H, Zhang L, Wang F, Yu D (2013) Arabidopsis transcription factor WRKY8 functions antagonistically with its interacting partner VQ9 to modulate salinity stress tolerance. Plant J 74:730-745

Ishikawa T, Uchimiya H, Kawai-Yamada M (2013) The role of plant Bax inhibiator-1 in suppressing $\mathrm{H}_{2} \mathrm{O}_{2}$-induced cell death. Methods Enzymol 527:239-256

Jain M, Mathur G, Koul S, Sarin N (2001) Ameliorative effects of proline on salt stress-induced lipid peroxidation in cell lines of groundnut (Arachis hypogaea L.). Plant Cell Rep 20(5):463-468

Kim MK, Lee BS, In JG, Sun H, Yoon JH, Yang DC (2006) Comparative analysis of expressed sequence tags (ESTs) of ginseng leaf. Plant Cell Rep 25(6):599-606

Kim JU, Hyun DY, Kim YC, Lee JW, Jo IH, Kim DH, Kim HK, Sohn JK (2015) Effects of salt in soil condition on chlorophyll fluorescence and physiological disorder in Panax ginseng CA Meyer. Korean J Med Crop Sci 23(6):446-453

Kjaersgard IVH, Jespersen HM, Ostergaard L, Welinder KG (1997) From sequence analysis of three novel ascorbate peroxidases from Arabidopsis thaliana to structure, function and evolution of seven types of ascorbate peroxidase. Biochem J 326(2):305

Koshiba T (1993) Cytosolic Ascorbate Peroxidase in seedlings and leaves of Maize (Zea mays). Plant Cell Physiol 34(5):713-721

Kubo A, Saji H, Tanaka K, Tanaka K, Kondo N (1992) Cloning and sequencing of a cDNA encoding ascorbate peroxidase from Arabidopsis thaliana. Plant Mol Biol 18:691-701

Kyte J, Doolittle RF (1982) A simple method for displaying the hydropathic character of a protein. J Mol Biol 157:105-132

Lad L, Mewies M, Basrani J, Scrutton N, Raven E (2002) Role of histidine 42 in ascorbate peroxidase-kinetic analysis of the H42A and H42E variants. Eur J Biochem 269:3182-3192

Leonardis SD, Dipierro N, Dipierro S (2000) Purification and characterization of an ascorbate peroxidase from potato tuber mitochondria. Plant Physiol Biochem 38:773-779

Lescot M, Déhais P, Moreau Y, De Moor B, Rouzéi P, Rombauts S (2002) PlantCARE: a database of plant cis-acting regulatory elements and a portal to tools for in silico analysis of promoter sequences. Nuc Acids Res. Database issue 30(1):325-327

Lichtenthaler HK (1987) Chlorophyll fluorescence signatures of leaves during the autumnal chlorophyll breakdown. J Plant Physiol 131(1):101-110

Liu J, Zhu JK (1998) A calcium sensor homolog required for plant salt tolerance. Science 280:1943-1945

Liu J, Ishitani M, Halfter U, Kim CS, Zhu JK (2000) The Arabidopsis thaliana SOS2 gene encodes a protein kinase that is required for salt tolerance. Proc Natl Acad Sci USA 97:3730-3734
Liu Z, Baoi H, Cai J, Han J, Zhou L (2014) A novel thylakoid ascorbate peroxidase from Jatropha curcas enhances salt tolerance in transgenic tobacco. Int J Mol Sci 15:171-185

Livak KJ, Schmittgen TD (2001) Analysis of relative gene expression data using real-time quantitative PCR and the 2(- Delta Delta CT) method. Methods 25:402-408

Lu Z, Liu D, Liu S (2007) Two rice cytosolic ascorbate peroxidases differentially improve salt tolerance in transgenic Arabidopsis. Plant Cell Rep 26(10):1909-1917

Luo MB, Liu F (2011) Salinity-induced oxidative stress and regulation of antioxidant defense system in the marine macroalga Ulva prolifera. J Exp Mar Bio Ecol 409:223-228

Maruta T, Tanouchi A, Tamoi M, Yabuta Y, Yosimura K. Ishikawa T, Shigeoka S (2010) Arabidopsis chloroplastic ascorbate peroxidase isoenzymes play a dual role in photoprotection and gene regulation under photooxidative stress. Plant Cell Physiol 51(2): 190-200

Menezes-Benavente L, Teixeira FK, Kamei CLA, Margis-Pinheiro M (2004) Salt stress induces altered expression of genes encoding antioxidant enzymes in seedlings of a Brazilian indica rice (Oryza sativa L.). Plant Sci 166:323-331

Mishra P, Bhoomika K, Dubey RS (2013) Differential responses of antioxidative defense system to prolonged salinity stress in salttolerant and salt-sensitive India rice (Oryza sativa L.) seedlings. Protoplasma 250:3-19

Mittler R, Zilinskas BA (1991) Molecular cloning and nucleotide sequence analysis of a cDNA encoding pea cytosolic ascorbate peroxidase. FEBS Lett 289:257-259

Miyake C, Asada K (1992) Thylakoid-bound ascorbate peroxidase in spinach chloroplasts and photoreduction of its primary oxidation product monodehydroascorbate radicals in thylakoids. Plant Cell Physiol 33:541-553

Najami N, Janda T, Barriah W, Kayam G, Tal M, Guy M, Volokita M (2008) Ascorbate peroxidase gene family in tomato: Its identification and characterization. Mol Genet Genomics 279:171-182

Orvar BL, Ellis BE (1995) Isolation of a cDNA encoding cytosolic ascorbate peroxidase in tobacco. Plant Physiol 108(2):839-840

Ozyigit II, Filiz E, Vatansever R, Kurtoglu KY, Koc I, Öztürk MX, Anjum NA (2016) Identification and comparative analysis of $\mathrm{H}_{2} \mathrm{O}_{2}$-scavenging enzymes (ascorbate peroxidase and glutathione peroxidase) in selected plants employing bioinformatics approaches. Front Plant Sci. doi:10.3389/fpls.2016.00301

Parre E, Ghars MA, Leprince AS, Thiery L, Lefebvre D, Bordenave M, Richard L, Mazars C, Abdelly C, Savouré A (2007) Calcium signaling via phospholipase $\mathrm{C}$ is essential for proline accumulation upon ionic but not nonionic hyperosmotic stresses in Arabidopsis. Plant Physiol 144:503-512

Rosa SB, Caverzan A, Teixeira FK, Lazzarotto F, Silveira JA, Ferreira-Silva SL, Abreu-Neto J, Margis R, Margis-Pinheiro M (2010) Cytosolic APx knockdown indicates an ambiguous redox responses in rice. Phytochemistry 71:548-558

Sanchez-Barrena MJ, Martinez-Ripoll M, Zhu JK, Albert A (2005) The structure of the Arabidopsis thaliana SOS3: molecular mechanism of sensing calcium for salt stress response. J Mol Biol 345:1253-1264

Sarowar S, Kim EN, Kim YJ, Ok SH, Kim KD, Hwang BK, Shin JS (2005) Overexpression of a pepper ascorbate peroxidase-like 1 gene in tobacco plants enhances tolerance to oxidative stress and pathogens. Plant Sci 169:55-63

Sathiyaraj G, Lee OR, Parvin S, Khorolragchaa A, Kim YJ, Yang DC (2011) Transcript profiling of antioxidant genes during biotic and abiotic stresses in Panax ginseng CA Meyer. Mol Biol Rep 38(4):2761-2769

Shafi A, Chauhan R, Gill T, Swarnkar MK, Sreenivasulu Y, Kumar S, Kumar N, Shankar R, Ahuja PS, Singh AK (2015) Expression of SOD and APX genes positively regulates secondary cell wall 
biosynthesis and promotes plant growth and yield in Arabidopsis under salt stress. Plant Mol Biol 87:615-631

Shi H, Ishitani M, Kim C, Zhu JK (2000) The Arabidopsis thaliana salt tolerance gene $S O S 1$ encodes a putative $\mathrm{Na}^{+} / \mathrm{H}^{+}$antiporter. Proc Natl Acad Sci USA 97:6896-6901

Shigeoka S, Ishikawa T, Tamoi M, Miyagawa Y, Takeda T, Yabuta Y, Yoshimura K (2002) Regulation and function of ascorbate peroxidase isoenzymes. J Exp Bot 53:1305-1319

Singh N, Mishra A, Jha B (2014) Over-expression of the peroxisomal ascorbate peroxidase $(\operatorname{Sbp} A P X)$ gene clonedfrom halophyte Salicornia brachiata confers salt and drought stress tolerance in transgenic tobacco. Mar Biotechnol 16:321-332

Sun WH, Duan M, Shu DF, Yang S et al (2010) Over-expression of $S t A P X$ in tobacco improves seed germination and increases early seedling tolerance to salinity and osmotic stresses. Plant Cell Rep 29:917-926

Tambussi EA, Nogues S, Araus JL (2005) Ear of durum wheat under water stress: water relations and photosynthetic metabolism. Planta 221:446-458

Teixeira FK, Menezes-Benavente L, Margis R, Margis-Pinheiro M (2004) Analysis of the molecular evolutionary history of the ascorbate peroxidase gene family: Inferences from the rice genome. J Mol Evol 59:761-770

Teixeira FK, Menezes-Benavente L, Galvão VC, Margis-Pinheiro M (2005) Multigene families encode the major enzymes of antioxidant metabolism in Eucalyptus grandis L. Genet. Mol Biol 28:529-538

Teixeira FK, Menezes-Benavente L, Galvão VC, Margis R, Margis-Pinheiro M (2006) Rice ascorbate peroxidase gene family encodes functionally diverse isoforms localized in different subcellular compartments. Planta 224:300-314

Tiwari V, Chaturvedi AK, Mishra A, Jha B (2013) The transcriptional regulatory mechanism of the peroxisomal ascorbate peroxidase (pAPX) gene cloned from an extreme halophyte, Salicornia brachiata. Plant Cell Physiol. doi:10.1093/pcp/pct172

Tsuda K, Somssich IE (2015) Transcriptional networks in plant immunity. New Phytol 206(3):932-947

Ulrich D, Aaron BS, Tomoaki H, Wei L, Guohua X, Julian IS (2014) Plant salt-tolerance mechanism. Trends Plant Sci 19(6):371-379

Venisse JS, Gullner G, Brisset MN (2001) Evidence for the involvement of an oxidative stress in the initiation of infection of pear by Erwinia amylovora. Plant Physiol 125:2164-2172
Verbruggen N, Hermans C (2008) Proline accumulation in plants: a review. Amino Acids 35(4):753-759

Wang Y, Wisniewski M, Meilan R, Cui M, Webb R, Fuchigami L (2005) Overexpression of cytosolic ascorbate peroxidase in tomato confers tolerance to chilling and salt stress. J Am Soc Hortic Sci 130(2):167-173

Webb RP, Allen RD (1995) Isolation and characterization of a cDNA for spinach cytosolic ascorbate peroxidase. Plant Physiol 108:1325

Wu G, Wang G, Ji J, Gao H, Guan W, Wu J, Guan C, Wang Y (2014) Cloning of a cytosolic ascorbate peroxidase gene from Lycium chinense Mill. and enhanced salt tolerance by overexpressing in tobacco. Gene 543:85-92

Yamaguchi K, Mori H, Nishimura M (1995) A novel isoenzyme of ascorbate peroxidase localized on glyoxysomal and leaf peroxisomal membranes in pumpkin. Plant Cell Physiol 36(6):1157-1162

Yan H, Li Q, Park SC, Wang X, Liu YJ, Zhang YG, Tang W, Kou M, Ma DF (2016) Overexpression of CuZnSOD and APX enhance salt stress tolerance in sweet potato. Plant Physiol Biochem 109:20-27

Yoshiba Y, Nanjo T, Miura S, Yamaguchi-Shinozaki K, Shinozaki K (1999) Stress-responsive and developmental regulation of $\Delta$ 1-pyrroline-5-carboxylate synthetase 1 (P5CS1) gene expression in Arabidopsis thaliana. Biochem Biophys Res Commun 261(3):766-772

Yoshimura K, Yabuta Y, Ishikawa T, Shigeoka S (2000) Expression of spinach ascorbate peroxidase isoenzymes in response to oxidative stresses. Plant Physiol 123:223-234

Zhang H, Wang J, Nickel U, Allen RD, Goodman HM (1997) Cloning and expression of an Arabidopsis gene encoding a putative peroxisomal ascorbate peroxidase. Plant Mol Biol 34:967-971

Zhang Q, Cui MA, Xin XUE, Ming XU, Jing LI, Wu JX (2014) Overexpression of a cytosolic ascorbate peroxidase gene, OsAPX2, increases salt tolerance in Transgenic Alfalfa. J Integr Agric 13(11):2500-2507

Zhu JK (2001) Plant salt tolerance. Trends Plant Sci 6(2):66-71

Zimmermann P, Hirsch-Hoffmann M, Hennig L, Gruissem W (2004) GENEVESTIGATOR. Arabidopsis microarray database and analysis toolbox. Plant Physiol 136:2621-2632 